\title{
The share of cooling electricity in global warming: Estimation of the loop gain for the positive feedback
}

\author{
Hamed Shakouri G. \\ School of Industrial and Systems Engineering, College of Engineering, University of Tehran, \\ Tehran, Iran. \\ Institute for Resource, Environment, and Sustainability (IRES), Electrical and Computer Engineering (ECE), UBC, Canada.
}

\begin{abstract}
The world's future is strongly connected to energy consumption trends. There are bi-directional relations between energy consumption and the average temperature of Earth, leading to positive causal loops. Increasing temperatures cause activity of more cooling systems most of which are electrified by burning hydrocarbons that consequently yield more carbon dioxide concentration and warmer climates. This paper is a trial to estimate the loop-gain by employing a bottom-up regional model. The model is a spreadsheet containing a sort of parameters and variables to estimate the amount of electricity used for cooling buildings in the residential and commercial sectors of 12 regions around the world. The share of fossilfuel based power plants determines the share of contribution of each region in $\mathrm{CO}_{2}$ emissions. Then by processing data on the global emission trend and land temperature anomaly, a linear ARMAX relationship is estimated to compute the loop-gain. The results show that, even in the optimistic scenario of IPCC (A1B), emission from cooling electricity will double up by the end of the century. With the estimated $1+1.4 \times 10^{-6}$ loop-gain, even if fossil-fuel electricity generation is gradually reduced to $40 \%$, it will decrease first but will start growing again in the century mid.
\end{abstract}

Keywords: Cooling electricity demand; Energy consumption; GHG emission; Global warming; Accelerating loops; Loop-gain estimation.

\section{Introduction}

Nowadays, nobody can neglect the global warming phenomenon, since most people can sense and see its consequences in all seasons of their life. Climate change acceleration has been a serious concern of researchers for decades [1]. The intergovernmental panel for climate change predicted that the average temperature of our planet will increase by $1.4-5.8{ }^{\circ} \mathrm{C}$ by the end of the $21^{\text {st }}$ century [2]. There are 
researches that propose more pessimistic estimates [3]. The warming speed has been estimated at more than $0.02^{\circ} \mathrm{C}$ per year for recent decades. Some researchers estimate the global warming from 1850 conditions to $2080-2100$ ranges from $1.5{ }^{\circ} \mathrm{C}$ to $4.4{ }^{\circ} \mathrm{C}$ under different scenarios [2]. They also address recent acceleration in warming. There exist an extensive literature that discusses the phenomenon by large models, among from System Dynamics (SD) models are of interest [4], used for policy analyses too [5].

The acceleration is probably because of positive feedbacks in the entire carbon concentration system addressed in the literature [3], some of which are represented by Figure 1. Three main resources of carbon dioxide are supplying the fuel for a long-term dynamics of this system: solar radiation, $\mathrm{CO}_{2}$ emitted by volcanic activities, and the only anthropological one, i.e. fuel burning by human beings. The first loop, denoted by $+\mathrm{R} 1$, which accelerates solar radiation absorption, is the effect of temperature rise on the polar ice melting, as well as fewer winter snows cover, which in turn causes expansion of oceans and more darkness of Earth's surface [6]. The second, $+\mathrm{R} 2$, is in fact inside the first; even more ocean expansion is in progress because of more waves and storms that eat the shores. Although the oceans act as a giant lung that absorbs $\mathrm{CO}_{2}$, scientists have found that its performance is a function of the atmosphere temperature. Thus, a third positive loop is activated weakening Earth's lungs and reduces both land and ocean uptake of $\mathrm{CO}_{2}$, respectively by $54 \%$ and $35 \%$, if the $\mathrm{CO}_{2}$ concentration is four folds [7]. The fourth positive loop has been also warned by scientists several times. The warming atmosphere speeds up the decomposition of belowground organic matter [8]. This also leads to more greenhouse gases (GHG) released into the atmosphere and closes another positive loop, $+\mathrm{R} 4$. The next positive loop, $+\mathrm{R} 5$, accelerates deforestation, including two other re-enforcing loops that worsen the case by decreasing rainfalls [9].

Before explaining the simple sixth loop, it is worth mentioning how critical is to study the dynamics of these loops. Although many articles have been modeling and analyzing the climate change phenomenon [10], not any paper has quantitatively discussed how exactly these loops affect climate change acceleration. Nonetheless, there are few papers that have estimated one of the individual loop gains, mostly focusing on the third loop. However, wild rapid changes, nonlinearities, and the complicated dynamics have made the researchers to revise and correct their estimates frequently [11].

The Global Carbon Project organization publishes the most recent reports revealing various statistics such as trends for carbon emission (CE) and global warming, as well as predictions of what can happen under different scenarios. The conceptual framework including most of the above-mentioned loops plus some other could be found in reports of the organization which are provided by collaborative efforts of the global carbon cycle science community [12].

Research shows that climate change has an undeniable impact on electricity consumption. The increase 
of cooling energy demand in Switzerland [13], California [14], and the entire United States [15], studied by researchers, are just a few examples for evidence of such impact. The warmer is going the weather the more electrical energy is needed for cooling and the more fossil fuel is burned for electricity generation. For instance, it is shown by simulation that the peak cooling energy use will increase in the US about 7\% to $9 \%$ in 2020 w.r.t. 1960 [15]. Moreover, the more fuel is consumed for either heating or cooling by electricity, the more important its side effects appear in the climate, i.e. the $\mathrm{CO}_{2}$ emission, global warming, and climate change [16]. This paper aims to analyze one of the factors of the warming acceleration represented by Figure 2.

On one hand, there are limited resources of energy, mostly fossil fuels. On the other hand, using fossil energy resources for both cooling and heating, with the consequence of $\mathrm{CO}_{2}$ emission, causes the average temperature of Earth to increase [17]. Figure 2 shows this mechanism in three loops. Energy consumed for cooling emits $\mathrm{CO}_{2}$ that accelerates warming in the middle loop, while in the left side loop, the energy required for heating decreases for the fact that the average temperature has a positive trend. In System Dynamics methodology these are called reinforcing and balancing loops respectively. Apparently, all reinforcing loops exacerbate the problem in the future of the global climate. Focusing solely on the positive trend, other probable positive loops due to colder winters and hotter summers, which are counted as a consequence of meandering phenomenon in jet streams [18], are not shown in these figures and need separate research to conclude their effects.

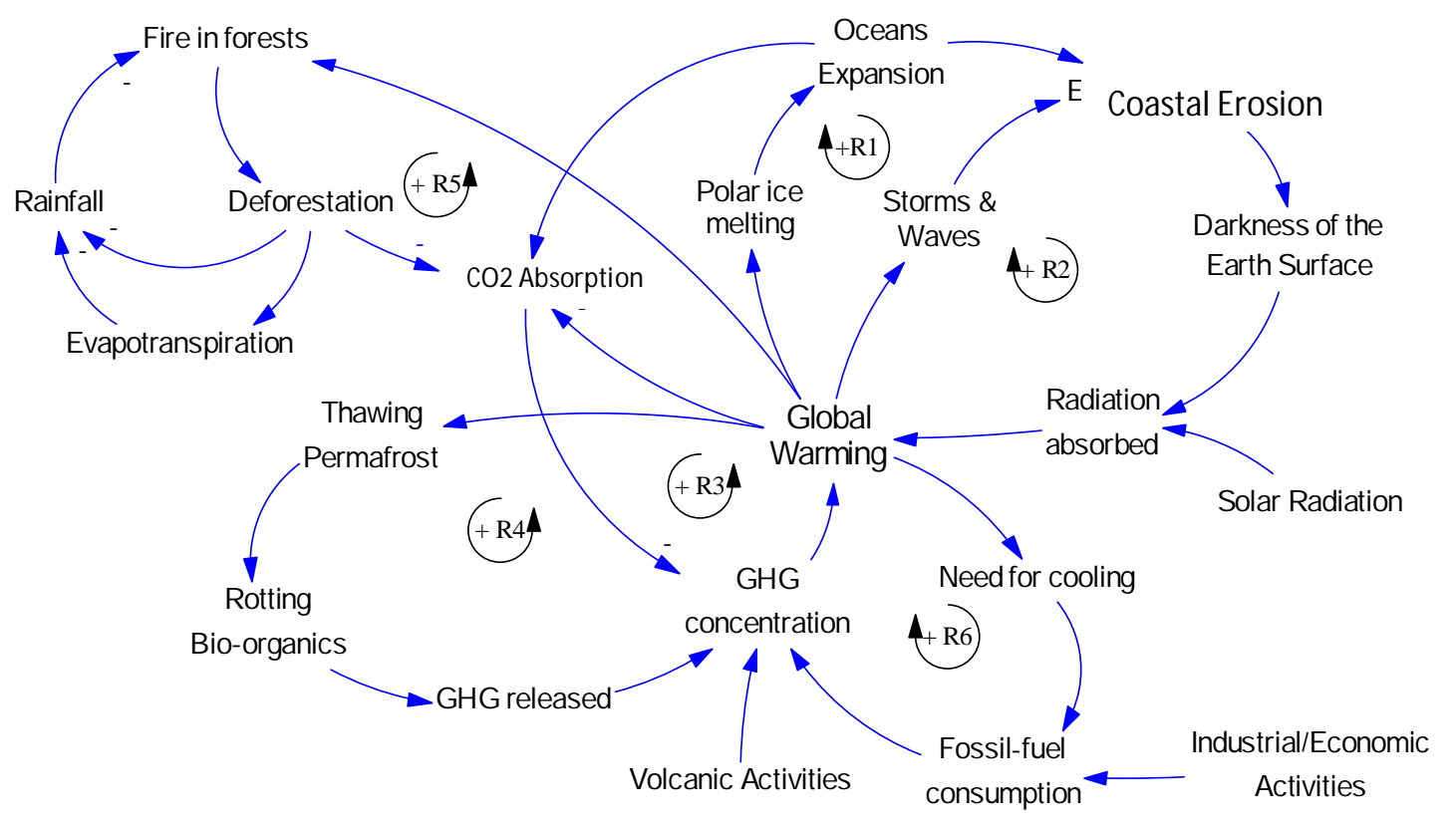

Figure 1: Causal loops relating energy consumption to climate change 


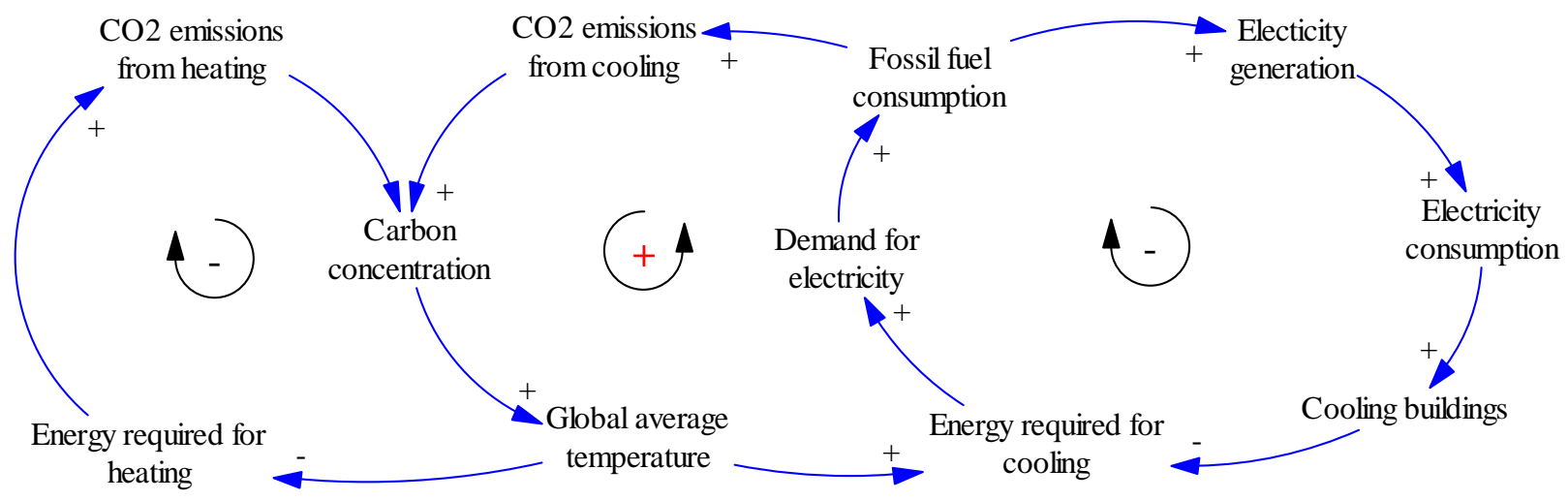

Figure 2: Causal loops relating energy consumption to climate change - Space cooling/heating loops

\section{(Each flesh indicates a cause-effect relationship.)}

Hence, researchers ought to think for any solution that adjusts the middle loop with a negative effect and attenuates the corresponding positive gain as much as possible.

Regarding the positive loop, one can make a rough calculation that energy needed for keeping a $100 \mathrm{~m}^{2}$ sample house $1{ }^{\circ} \mathrm{C}$ colder than the outdoor temperature for an hour is approximately $0.5 \mathrm{kWh}$. This energy is mostly provided by electricity, which can be generated by fossil fuels or renewable (clean/carbonless) energies. Both technologies based on cooling by fossil fuel directly, or by fuel-based electric power cause $\mathrm{CO}_{2}$ emission which in turn leads the average temperature of the globe to increase, and so need more energy for cooling. Moreover, other energy demand supplied by fossil fuel, especially in the industrial and transportation sectors, accelerates the warming loop even more. Adding these factors to Figure 2 in its right-hand loop leads to what is presented in Figure 3.

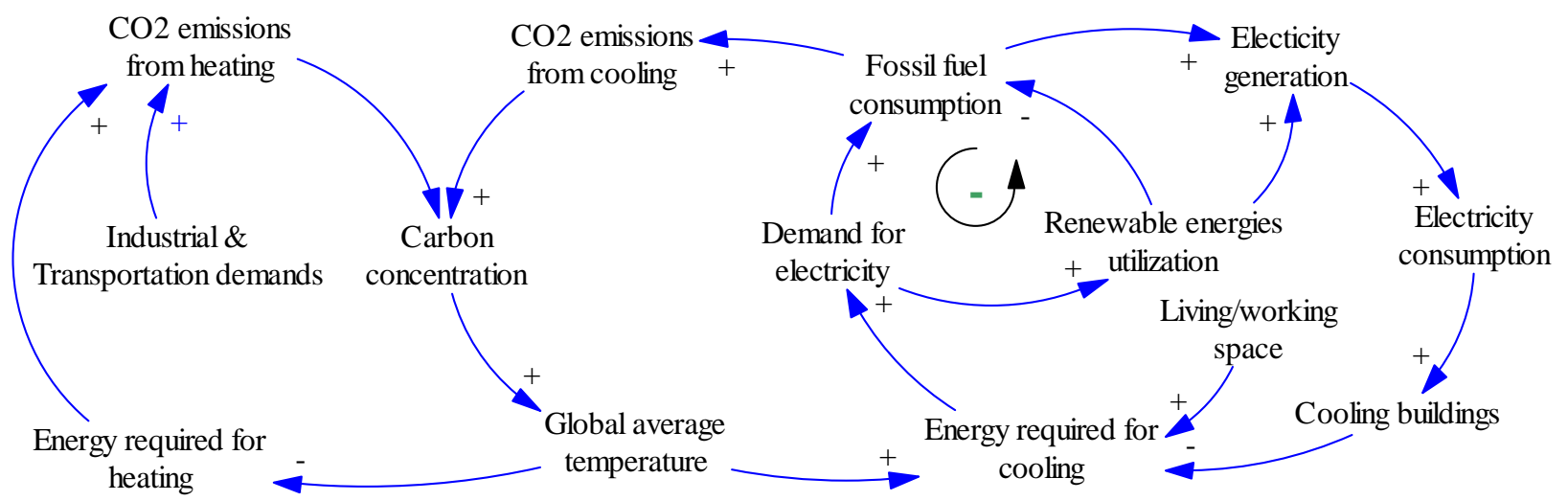

Figure 3: Space cooling needs electricity that is generated by either fossil fuel or renewable resources.

Since the energy required for heating is mostly demanded by industries that mainly use fossil fuels, the left-hand side balancing loop is too weak to compensate for the destabilizing effect of the other reinforcing loop. However, if electricity generated by renewable resources is promoted and increased, fossil fuels 
consumption will reduce, and the warming rate of the global climate will be lowered. Therefore, it seems essential to investigate climatic factors effect on energy consumption in two warm and cold seasons separately.

There are a few studies reporting estimates on the share of cooling electricity in the total electricity consumption all around the world. Although there are accurate engineering methods to calculate the heating/cooling loads, on large-scale, e.g. for a country, it is too difficult to estimate the total worldwide load by such detailed methods. Detailed bottom-up electricity demand estimates are performed for buildings of the European service sector [19], A household energy use breakdown is done in 2009 for the United States [20]. The researchers have found that almost $11 \%$ and $14.1 \%$ of electricity is consumed for cooling and air-conditioning in these two regions, respectively. Updates can be found for 2014 in Europe [21] and 2015 in the US [22], which refer to $13.7 \%$ and $18 \%$, respectively. There are many other works that address how temperature and other climatic variables can impact electricity consumption, both from a technical viewpoint [23]-[24], or in a macro level for a specific city or country [25]-[26].

This paper aims to follow up a bottom-up analysis of electricity use in the world and then present a simple method for estimating the loop gain that is comparable with the results obtained by other top-down electricity demand models. An intelligent design of electricity demand model for a sample residentialcommercial region [24]-[31], which includes climatic variables, particularly the temperature, might be used to estimate the total electricity used for cooling. The results are compared with those could be found in the literature to confirm the accuracy of the estimates. Finally, gathering data for the share of fossil-fuel based power plants, the total GHG emissions are calculated and then the global warming acceleration rate caused by cooling the residential-commercial sectors is estimated.

The organization of the paper is as follows. The second section is dedicated to the analysis of electricity demand for space cooling through a bottom-up approximate, yet complicated and efficient model. It is tried to relate almost everything to the temperature. Then the calculation is tracked for a sample region and the results are summarized for 12 regions of the world. In the next section, by using linear approximate models the relationship between GHG emission and the average global temperature anomaly is estimated, where the loop gain is found. A long-term simulation is also designed in two scenarios and the results are compared. Section four concludes the paper.

\section{The regional analysis of electricity demand for space cooling}

There are too many works on the estimation of the energy demand of buildings [27]. They utilize various techniques and methodologies [28]. The methods applied for the estimation of buildings cooling/heating 
energy demands are classified into two main groups: statistical and engineering methods [29]. The engineering methods can be divided to elaborate and simplified methods, based on the availability of data and the accuracy needed. However, there is no apparent boundary to separate the simplified and elaborate models [30]. Elaborate engineering (bottom-up) method is indeed the most accurate [23], [31]; however, it is almost impossible to collect all data for all parameters needed for a thorough calculation. Instead, statistical data analysis (top-down) methods can result in almost accurate estimates too, if they consider all the relevant socio-economic, dwelling and appliance-related factors [32]. Evidently, the critical factors affecting energy consumption in buildings include human behavioral elements [33]. Hence, hybrid methods that benefit from statistical data and consider both technical and human-being based factors can be applied as well [34]. However, in this paper, a simplified version of the engineering method is followed to overcome the lack of detailed data for all regions across the world. Moreover, statistical data of energy consumption is used to verify the results, wherever available.

To approximate the energy demand for cooling houses/working spaces all over the world, a regional division is applied to the worldwide available data. The world regions are grouped into six groups: North America (USA and Canada), Europe (including Eurasia and Russia), Oceana, Asia (West Asia, South Asia, Southwest Asia, Central Asia and Middle East), Africa (North Africa and Sub-Saharan Africa) and Latin America (including Central America and Caribbean). In the rest of this paper, each of these 12 regions is indexed by $k$, appearing as a subscript for the variables and parameters. In addition to climatic factors, i.e. temperature and humidity, this division considers other demographic and social specifications including households, living space sizes, cooling equipment penetration, as well as other technical parameters including the fossil-fuel share for electricity generation, efficiencies, energy wastes, etc. For each of the regions, based on data gathered for these factors, the energy needed for cooling is estimated. Table 1 exhibits a list of categorized factors.

Table 1: Factors influencing electricity need for cooling of living and working spaces

\begin{tabular}{|c|c|c|c|c|}
\hline Category & \multicolumn{4}{|c|}{ Sub-categories } \\
\hline Demographic & Population & Household size & Homeless & \\
\hline Residential & Per capita living space & A typical house specifications & Technical & Architecture \\
\hline Weather & Summer temperature data & Regional solar radiation data & Warm hours and days & \\
\hline Commercial & Per employee working space & Labor force & Unemployment rate & \\
\hline Electricity & Cooling equipment penetration rate & Generation system specifications & Fossil fuel shares & \\
\hline
\end{tabular}




\subsection{Approximate cooling load of buildings via a bottom-up formulation}

To keep the temperature of a living space of $A\left[\mathrm{~m}^{2}\right]$ comfortable, the heat rate from walls, roof, and windows should be compensated by a cooling (heating) equipment. The electric power of a cooling system for each typical house in region $k$ should be able to compensate the following heat rates, caused by the well-known heat transfer modes; conduction, convection, and radiation [35]-[36]:

1) Heat entering from the surfaces because of indoor-outdoor temperature difference,

2) Heat generated by the residents' bodies, lights, and other equipment,

3) Global sun radiation heat that transfers to the living space through the walls, In addition, cooling systems usually consume electricity for air conditioning and ventilation, which stands as the fourth part:

4) Electricity for ventilation and air conditioning (VAC).

These parts are first formulated per household and per one degree of temperature difference. Then, the total buildings square meter which is assumed to be proportional to the number of households, who utilize an electrical cooling system in each region, or employees in workspaces will be used as bases to estimate the total cooling load. After relating the load to temperature differences, the well-known degree-hours method converts the load to energy. The share of cooling energy demand in total electricity consumption, reported by [19], [20], [21], and [22] for Europe and the US, will be the criteria to verify final results obtained by formulations and approximations.

\subsubsection{Buildings Cooling Load}

To estimate the cooling load of buildings, the focus is first on the residential sector. The results are extended to cover the commercial sector, based on some specifications of the sector, such as working space and employment ratio, to obtain an acceptable estimate of cooling energy demand of all buildings utilized for dwellers, services, commercial, public purposes, etc. Finally, available statistics are used to verify the estimates and adjust by tuning some uncertain parameters.

Based on the Fourier's law of heat transfer through conduction, the basic formula: $Q=A$.(K/L). $\Delta \theta$ can be manipulated to include all the heat rates incoming to a house with four walls, roof, celling, and several windows in separate. Hence, the first part is heat transfer from the surfaces, i.e. walls, ceiling, floor, and windows:

$$
P_{k, 1}=4 H_{k} \sqrt{A_{k}}\left\{\frac{q_{\text {roof }, k}}{4 f_{k} H_{k}} \sqrt{A_{k}}+q_{\text {wall }, k}\left(1-w_{k}\right)+q_{\text {win }, k} w_{k}\right\}(\Delta \theta)_{k} \quad \text { [W] }
$$

where $\Delta \theta(t)=\theta(t)-\theta_{d}$ is the indoor-outdoor temperature difference, $A\left[\mathrm{~m}^{2}\right]$ is the house size, which is 
assumed in a square shape, $H[\mathrm{~m}]$ is its wall's height, $w[\%]$ is window-wall ratio, and $q_{\text {wall }}$ and $q_{\text {win }}$ $\left[\mathrm{W} /{ }^{\circ} \mathrm{C} / \mathrm{m}^{2}\right]$ are the heat transfer coefficients of the walls/roof and windows respectively (known as Uvalues). It is assumed that the buildings in each $k^{\text {th }}$ region are $f_{k}$-floor in average, so that one of every $f$ roofs/floor among all houses are exposed to the outside temperature. Also, it is assumed that the heat transfer coefficient of the roof is half of that of the walls.

The second part includes heat emission from the body of residents, plus bulbs that are on at the night.

$$
P_{k, 2}=120 b_{k}+10 A_{k} \quad[\mathrm{~W}]
$$

It is assumed that each alive body inside a building emits about $120 \mathrm{~W}$ [16], so $b_{k}$ is the number of persons living/working indoors. Also, if incandescent light bulbs are commonly in use, in average $10 \mathrm{~W}$ is needed to light on each square meter (about 200 lumen $/ \mathrm{m}^{2}$ by bulbs with the efficiency of about 20 lumen/W). Since the cooling load in summers may happen in night dark or in daylight, let us assume that only $50 \%$ of the load happens at night. Hence, the coefficient for heat generated by bulbs is halved, i.e. $5 \mathrm{~W} / \mathrm{m}^{2}$ is replaced for the corresponding coefficient in the formula.

Last, but not least, is the sun radiation effect which is the most important part of heat transfer to a building, especially when it is exposed to direct sunlight. Like the formulation of (1), this part is calculated by:

$$
P_{k, 3}=\frac{A_{k}}{f_{k}} r_{\text {roof }, k}+4 H_{k} \sqrt{A_{k}}\left\{r_{\text {wall }, k}\left(1-w_{k}\right)+r_{\text {win }, k} w_{k}\right\} \quad[\mathrm{W}]
$$

The components are like that of (1), except that $r_{\text {roof }}, r_{\text {wall }}$ and $r_{\text {win }}\left[\mathrm{W} / \mathrm{m}^{2}\right]$ are solar irradiances absorbed and transmitted into the house from the roof, walls and windows, respectively [35]. These terms are replaced for $q \times \Delta \theta$ products in (1) to represent heat transfer caused by sun radiation. Avoiding complicated calculations with azimuth and altitude angles that are dependent on regions latitude, days of a year and hours of a day, we had to follow some simplified relations. To relate the heat rate in (3) to the temperature, first we use an approximate version of (3) by factorizing the global irradiance:

$$
P_{k, 3}=2 H_{k} \sqrt{A_{k}}\left\{\frac{p_{\text {roof }, k}}{4 f_{k} H_{k}} \sqrt{A_{k}}+p_{\text {wall }, k}\left(1-w_{k}\right)+p_{\text {win }, k} w_{k}\right\} r_{g, k} \quad \text { [W] }
$$

where $r_{g, k}\left[\mathrm{~W} / \mathrm{m}^{2}\right]$ is the global (a combination of the direct, diffuse and reflected) irradiance, averaged over summer days of the region $k$, and $p_{\text {roof }}, p_{\text {wall }}$ and $p_{\text {win }}[\%]$ are overall receiving-absorption-transmission coefficients for the roof, walls and windows respectively. Each coefficient is formed by three parts: absorption percentage, transmission percentage, and the incidence angle (to adjust local radiation angle with that of the basis region). The transmission percentage is related to the surface heat transfer coefficients by a linear regression estimated using experimental data in [35] as:

$$
\gamma_{j, k}=0.22 q_{j, k}-0.0032 ; 0.1 \leq q_{j, k} \leq 0.7
$$

Hence, the following coefficients should be used: 


$$
p_{j, k}=\beta_{j, k} \gamma_{j, k} \sin \left(\delta_{j, k}\right) ; \quad j \in \mathrm{S}=\{\text { roof, wall, window }\}
$$

where $\beta_{j, k}$ is the decimal part of the radiation absorbed by the surface $j$, and is assumed to be $70 \%, 50 \%$ and $80 \%$ for the three members of the surfaces set, S, respectively [35]. In addition, sunlight altitude angle is represented by $\delta_{j, k}$, so we have: $\delta_{\text {wall,k }}=\delta_{\text {window }, k}=90-\delta_{\text {roof }, k}$; where

$$
\delta_{\text {roof }, k}=113.45-\text { latitude }_{k}
$$

is found for the highest irradiation in summer, given the average latitude angle for the $k^{\text {th }}$ region in degrees. Finally, the total heat load which should be pumped out of the typical house in the $k^{\text {th }}$ region for cooling a building is found by summing up the three parts (1), (2), and (4), as follows:

$$
P_{k}=P_{k, 1}+P_{k, 2}+s_{k} P_{k, 3} \quad[\mathrm{~W}]
$$

Due to the shadows of clouds, other building, trees, etc., not all the houses are exposed to sunlight energy from windows or walls all the daytime; thus, the third term is multiplied by an adjustment ratio, $s_{k}$, which is about 0.25 to 0.35 depending on the density of buildings and trees, etc., to exclude the hours that buildings are not receiving direct irradiations.

This amount of heat that warms up a typical house is pumped out by a cooling device, the performance of which is called the Coefficient of Performance $(C o P)$ of the appliance. The electrical energy required to cool a house should be multiplied by the number of houses (buildings) with cooling systems. We have also to add an extra electrical power needed for ventilation and air conditioning (VAC), which is experimentally approximated by [37]:

$$
P_{k, 4}=1.23\left(0.15 A_{k}+3.5 b_{k}\right)(\Delta \theta)_{k} \quad[\mathrm{~W}]
$$

where the parameters have the same definitions as in (1) or (2).

Since energy is simply calculated by the product of time and power, summarizing all the components explained above in one formulation, the total electricity to supply the total demand for cooling residential is estimated by:

$$
E_{k_{-} \text {residential }}=10^{-9}\left\{\left(\frac{P_{k, 1}+s_{k} P_{k, 3}}{\operatorname{CoP}_{k}}+P_{k, 4}\right) \cdot \frac{D h_{k}}{(\Delta \theta)_{k}}+\frac{P_{k, 2} \cdot h_{k}}{\operatorname{CoP}_{k}}\right\} \cdot N_{k}[\mathrm{GWh}] .
$$

In this formulation, $D h_{k}$ represents the total Degree-hours of region $k$ during warm hours in a summer (see Figure 5), $h_{k}$, defined as:

$$
D h_{k}=\sum_{\text {warm hours }} \Delta \theta(t)=\sum_{h_{k}}\left\{\theta_{h_{k}}-\theta_{d}\right\}
$$

where $\theta_{d}$ is the desired temperature in summer days, and $N_{k}$ denotes the number of houses employing coolers in the $k^{\text {th }}$ region. 


\subsubsection{Estimation of Commercial Buildings Cooling Load}

Cooling load of a building depends mostly on the physical specifications, although the behavioral factors affect energy consumption as well. However, as mentioned above, this research is focusing on a simplified engineering method including demographic data to estimate cooling electricity consumption, by world regions. This is cumbersome enough and includes unavoidable uncertainties. Differentiation between behaviors of people using buildings in various regions around the world is much more complicated, and so is ignored herein.

In addition to (10), now we must consider energy needed for cooling working spaces (building) in all other sectors (commercial/public, manufacturing and industrial). Knowing that repeating the above calculation for all various types of these buildings in all regions is extremely cumbersome or even impossible. There is no detailed data for specifications of all types, and based on an assumption that there is not a big difference between the specifications in average [21], a simplified approximate extension is applied here. To obtain an appropriate estimate for the total cooling load, including commercial buildings, the following approximation is applied in this research:

$$
E_{k}=E_{k_{-} \text {res }}\left(1+\frac{\text { No of employees }}{\text { No of households }} \times \frac{\text { Square meter for an employee }}{\text { Square meter for a household }} \times \text { Correction Coefficient }\right)
$$

where, $E_{k_{-} r e s}$ is calculated by (10) considering the households only. The last ratio in (12) is assumed to be about 1.1 to 1.3, varying for various regions. This adjustment is justified below, based on the existing researches.

Statistics on the cooling load of buildings used for workspace are not available. However, a few research works can be found in comparing total energy use by buildings dedicated to various purposes. Some report an average of $39.75[\mathrm{kWh} / \mathrm{m} 2]$ for cooling energy demand in commercial buildings in Europe [19] is reported. Averaging the demand for all the buildings (including houses, apartments and offices) among ten cities with various climates around Europe comes to $26.6,14.5$ and $27.7\left[\mathrm{kWh} / \mathrm{m}^{2}\right]$, respectively; hence the load is almost the same for houses and offices but about 50\% less demand is for apartments [21]. These numbers, which will are considered as bases for verification of the results obtained for both sectors, indicate about 30\% difference in specific cooling energy between the two sectors, knowing that most of the households live in apartments (the statistics for EU-28 [38] implies that the ratio was 58\% in 2015, and so, the ratio of residential to commercial cooling load would be around $70.7 \%)^{*}$.

\footnotetext{
* According to EU statistics: "In 2015, more than 4 out of every 10 persons (42.0 \%) in the EU-28 lived in flats ...". Thus, the average specific cooling load for the residential demand would be: $42 \%$ x $26.6+58 \%$ x $14.5=19.58$ [kWh/m2], which is $70.7 \%$ of 27.7 [kWh/m2].
} 
Although many behavioral and technical factors may affect this, regardless of other factors, it can be related to the difference between the heights of buildings in the two sectors. Based on the above statistics, it seems that for developed countries 1.25 to 1.3 is a proper adjustment, while for others it is assumed lower, regarding the fact that the official buildings are less equipped by cooling systems. This can be verified by comparison of electricity demand in the sectors of different countries around the world. It is a fact that the total electricity consumption by these two sectors in developed countries, e.g. the US and European countries are almost the same, while in non-OECD countries commercial sector consumes almost half of the households [39]. Clearly, the gap is mainly because of fewer devices that can be found in offices, hotels, restaurants, schools, and universities of less developed countries. Nevertheless, the specific cooling electricity is somewhat higher than what is consumed in residential buildings, for differences in both building specifications and people's behavior.

\subsubsection{GHG Emission Estimate}

The electricity demand obtained in (12) should be divided by the overall efficiency of transmissiondistribution and fossil fuel electricity generation systems to result in the total fossil fuel primary energy required for cooling houses in the $k^{\text {th }}$ region, assuming that only $\varphi_{k}$ percent of electricity is generated in fossil fuel power plants [41]:

$$
F_{k}=\frac{\varphi_{k}}{\eta_{k}} E_{k} \quad[\mathrm{GWh}]
$$

where $\eta_{k}=\eta_{G, k} \times \eta_{T D, k}$ is found by the production of efficiencies of electricity generation [40] and transmission-distribution systems in each region [39]. The emission factors equal to 2.08, 1.22 and 1.68 $\mathrm{kgr}$ of $\mathrm{CO}_{2}$ per kWh of electricity generated by power plants using each of coal, NG and oil products, respectively, are then applied to find the total emission for cooling electricity. The required data, such as the share of fossil fuel in electricity generation and shares of power plant types, are obtained from various references including [39], [40], [41], [42] and [43].

\subsection{Relating solar radiation to air temperature}

For our specific goal of estimating the positive loop gain in Figure 2, we must relate solar global radiation to the air temperature. There are many experimental static models that estimate global radiation to daily minimum and maximum air temperatures and their difference:

$$
\Delta \bar{\theta}=\theta_{\max }-\theta_{\min }\left[{ }^{\circ} \mathrm{C}\right]
$$

Almost all the models use the total daily extraterrestrial radiation calculation which has quite straightforward computations for any specific day of a year, given the latitude for any specific location on 
the Earth [44]. For example, given the solar constant to be 1367 [W/ $\left./ \mathrm{m}^{2}\right]$ the total radiation to the horizontal surface at top of the atmosphere, namely $H_{0, k}$, is found to be around $11-12\left[\mathrm{kWh} / \mathrm{m}^{2}\right.$-day] in summer for most regions with latitudes between $0^{\circ}$ to $\pm 65^{\circ}[44]$. The simplest way for relating it to the temperature difference was a one-parameter model proposed by Hargreaves and Samani in 1982 [45]:

$$
H_{g, k}=a_{1} \cdot H_{0, k} \cdot(\Delta \bar{\theta})^{0.5} \quad\left[\mathrm{Wh} / \mathrm{m}^{2} \text {-day }\right]
$$

The ratio of $K_{\mathrm{T}}=H_{g, k} / H_{0, k}$ is called clearness index which is dependent on factors such as humidity and cloudiness. The formula is calibrated parametrically to fit characteristics of different locations [46] with different characteristics such as arid and semiarid regions [47]. The history of works attempting to find a relationship between solar irradiation and temperature is a long one [48]; however, for this study, the simplicity of the original formula suffices. Statistical data shows that in summer days the clearness index is around 0.45 to $0.67(\mu \pm \sigma)$ for almost all regions [49]. Many other models are also developed in a wide range of complexity [50], from using linear regressions to implementing artificial neural networks [51]. However, these models are not applicable for our purpose, first because of the "non-causality" problem that almost all the models have (because they use temperature data to estimate solar irradiation), and second, for their complexity and the vast number of variables and data requirement. Evidently, it is a fact that the air temperature is a function of solar radiation. Hence, ignoring all other factors, such as wind and humidity, we can write:

$$
\theta(t)=\theta_{\min }+f\left(\int_{\text {sunrise }}^{t} H_{g}(\tau) d \tau\right) \quad\left[{ }^{\circ} \mathrm{C}\right] .
$$

Nevertheless, the models are following the opposite direction by estimating average irradiation based on temperature data. So, non-causality appears in most of the models in the literature. However, for the specific purpose of this research, a simple model is adequate to relate the global irradiation to the temperature with an approximate relation.

In this research, sets of 10-minute data for daily temperature, radiation and wind in summer for a moderately dry climate zone, Nahavand $\left(34.18^{\circ} \mathrm{N}, 43.37^{\circ} \mathrm{E}\right)$, is used to develop a linear dynamic causal relation that connects daily temperature variation, $\theta_{t}$, to the global irradiance, $H_{g}$, and the wind speed, $w_{t}$ (See the Appendix: ARMAX models):

$$
\theta_{t}=\theta_{\min }+\sum_{i=1}^{n_{\alpha}} \alpha_{i} \theta_{t-i}+\sum_{i=0}^{n_{\beta}} \beta_{i} H_{g}\left(t-t_{i}\right)+\sum_{i=0}^{n_{\omega}} \omega_{i} w_{t-i}+\sum_{i=0}^{n_{\gamma}} \gamma_{i} e_{t-i} \quad\left[{ }^{\circ} \mathrm{C}\right] .
$$

where $e_{t}$ is a white noise unknown error term. Many different time periods and parameters number $\left(n_{p}\right.$ 's) are examined by the ARMAX model, and based on the DC gain of the best selected model [52], the relation is approximated by:

$$
\Delta \theta=a^{\prime} . H_{g} ; \quad a^{\prime} \cong 0.01412
$$


with $H_{g}$ denoting the global irradiation per day. This is quite compatible with the linear slopes obtained for high radiation at warm and hot temperatures in Figure 4.

Moreover, a static relationship is estimated fitting various curves to the data of cooling degree-hours of 420 sample days (of four summers) versus the cumulative daily radiations in warm hours. The results are shown in Figure 4, as well.

However, like as the clearness index, this coefficient also depends on various factors, mostly the altitude and relative humidity. To verify the coefficient, we have also estimated the coefficient $a^{\prime}$ in (18) using hourly data for summer days, in a sample region, Los Angeles $\left(34.05^{\circ} \mathrm{N}, 118.25^{\circ} \mathrm{W}\right)$, with the same latitude but a very lower latitude and higher humidity, resulting in $a^{\prime} \cong 0.00945$. The corresponding data is illustrated in Figure 5 for a sample warm (July) summer day of that sample region.

For the lack of any probability density function for the clearness index, this range of uncertainty is dealt with by means of fuzzy numbers. Replacing the inverse of (18) in (4) in terms of the midday average extraterrestrial radiation for each region, $H_{0, k}$, we will obtain a fuzzy ${ }^{\dagger}$ value as an effective irradiation in the third term of the cooling load:

$$
\widetilde{H}_{g, k}=\widetilde{K}_{T, k} \cdot H_{0, k},
$$

where,

$$
\widetilde{K}_{T, k}=\frac{(\Delta \bar{\theta})_{k}}{\tilde{a}}
$$

is a fuzzy clearness index for the $k^{\text {th }}$ region, obtained based on the average maximum temperature difference in summer and a fuzzy coefficient, $\tilde{a}=(7.75,1.85)$, which is a triangular fuzzy coefficient with a center equal to 7.75 and spread of 1.85 . Since $a=1 /\left(a^{\prime} H_{0}\right)$, its fuzzy set is obtained multiplying the two sides of $H_{0, k}$ (e.g. $10.5\left[\mathrm{kWh} / \mathrm{m}^{2}\right.$-day $]$ and $11.7\left[\mathrm{kWh} / \mathrm{m}^{2}\right.$-day]), by the two values found for $a^{\prime}$. This way, $\widetilde{K}_{T, k}$ is obtained between 0.494 to 0.693 in average for these regions, by which the third term can be rewritten in terms of the temperature difference, if only we can relate $(\Delta \bar{\theta})_{k}$ to $(\Delta \theta)_{k}$. It should be noted that $\theta_{\min }$ is usually lower than $\theta_{d}$ in (11), so $\Delta \theta$ here differs with that of the indoor-outdoor difference, i.e. $(\Delta \theta)_{k}>(\Delta \bar{\theta})_{k}$, which is assumed to be around $2^{\circ} \mathrm{C}$ to $3^{\circ} \mathrm{C}$, depending on the humidity, not exceeding $4.5^{\circ} \mathrm{C}$ for the driest regions. This value is adjusted for each $k^{\text {th }}$ region such that the uncertainty range, i.e. the spread obtained for the fuzzy clearness indexes, $\widetilde{K}_{T, k}$, fall in the ranged obtained from the statistics in

\footnotetext{
$\dagger$ Many other parameters and variables could be easily considered as fuzzy numbers, assuming a center value ( $\mu$ : average), and a spread ( $\sigma$ : deviation) and presented for instance as: $\tilde{u}=(\mu, \sigma)$. However, since we have used the average values, this doesn't significantly impact final conclusions.
} 
[49], with the sense of equality possibility that fuzzy numbers can have [53].

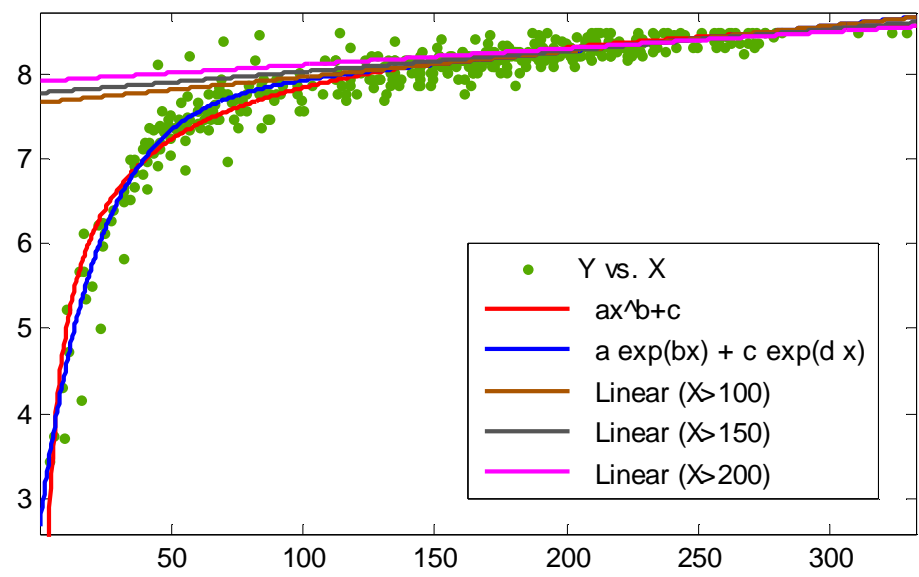

Figure 4: Hot (warm) hours cumulative sun radiation ( $\mathrm{Y}$ in $\mathrm{kWh})$ versus cooling degree-hours $\left(\mathrm{X}\right.$ in ${ }^{\circ} \mathrm{C}$-hrs) measurements in Nahavand. Nonlinear and partially linear curve fitting results are also included.

\subsection{Emission estimate via an example region: Europe}

The above bottom-up calculation is applied for all the 12 regions around the world, the results of which are given in this section. We are also following the calculations for an example region. Because of more accurate and accessible data Europe region is chosen, to which Russia is augmented, and the specifications for buildings are assumed as follows:

The average living space is about $105 \mathrm{~m}^{2}$ per household [58], with about $H=3 \mathrm{~m}$ of wall height on average. The windows cover about $w=20 \%$ of the walls surface, and $q_{\text {wall }}$ and $q_{\text {win }}$ are assumed to be 0.9 and 2.7 $\mathrm{W} / \mathrm{m}^{2}-^{\circ} \mathrm{C}$, respectively (somewhat lower than the average U values in Table 2 of [21]).

Then, according to (1), the "per degree" part of $P_{\text {Europ, } 1}$ for each typical house is estimated around 138 $\mathrm{W} /{ }^{\circ} \mathrm{C} / \mathrm{hh}$, where with a rough average temperature difference of $5^{\circ} \mathrm{C}$ between outdoor temperature and the convenience temperature for summer days:

$P_{\mathrm{EU}, 1}=687[\mathrm{~W} / \mathrm{hh}]$.

Given that the average household size is 2.4 , the second part is estimated by (2) as:

$P_{\text {EU,2 }}=809[\mathrm{~W} / \mathrm{hh}]$.

To calculate the third part, knowing that the latitude is between $40^{\circ}$ to $65^{\circ}, H_{0, k}$ is obtained averagely around $40[\mathrm{MJ}](39.1$ to 41.5 ; i.e. $11.1 \mathrm{kWh})$, and so, $\widetilde{H}_{g, k}=(3.99,0.671)[\mathrm{kWh} / \mathrm{hh} /$ day $]$ is found by (19). Finally, by assuming that the warm hours of a summer day in Europe is roughly $h_{\mathrm{EU}}^{w}=8$ hours (e.g.

10 am to $6 \mathrm{pm}$, based on the illustration in Figure 5), a fuzzy $\tilde{r}_{g, k}=\widetilde{H}_{g, k} / h_{k}^{w}$ is applied into (4), and a fuzzy $P_{\mathrm{EU}, 3}$ is found, which is simply defuzzified by averaging to obtain $s_{\mathrm{EU}} P_{\mathrm{EU}, 3}=1401$ [W/hh]; while $s_{k}$ in (8) is assumed to be $25 \%$. This parameter is indeed one of the most sensitive parameters which are 
adjusted so that the results admit the existing statistics.

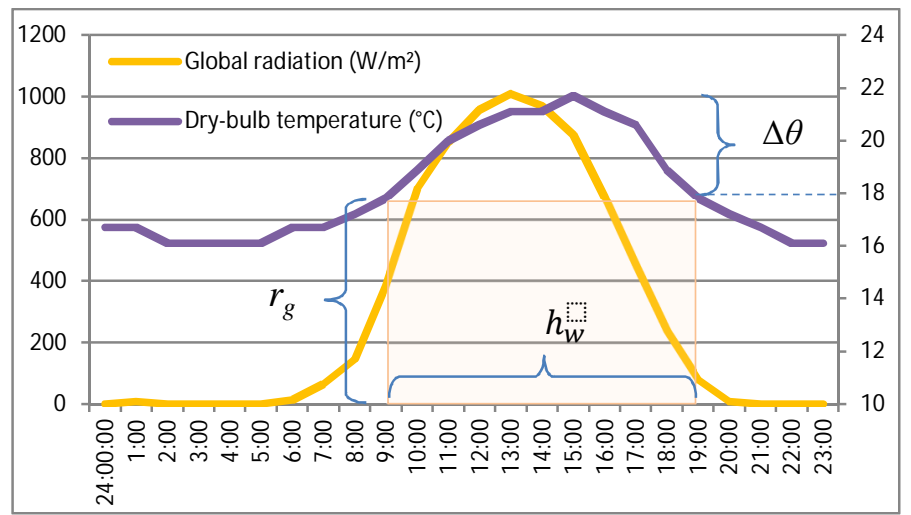

Figure 5: Illustration of the variables defined for relating the solar radiation to the temperature difference based on variations of the solar radiation and temperature in a sample summer day of a sample region.

There is a straightforward calculation to obtain $P_{\mathrm{EU}, 4}=147.7 \mathrm{~W}$ per household.

The other parameters and assumptions to be put in (10) and (12) to estimate the total electricity needed for cooling in Europe are as follows:

- No of households (2014): 308 million (0.1\% homeless are excluded),

- Total cooling degree-hours in a year (estimated from cooling degree-days in [57], and [59]-[61]):

$D h_{k}=110$ (days) $\times 8$ (hours $) \times 5$ (degrees $)=4400$,

- Cooling appliance penetration rate: $60 \%$ [42]

- Cooling appliance average coefficient of performance: $C o P_{\mathrm{EU}}=3.7$

- Labor forces: 366 million (2014) [62][42]

- Unemployment: $11.6 \%$ (2014) [62][42]

- Average working space: $30 \mathrm{~m}^{2}[21]$

Thus, through (10) we have estimated that cooling of the residential and total buildings need around $E_{\mathrm{EU} \_r e s}$ $=151 \mathrm{TWh} /$ year, i.e. $13.8 \%$ of the total electricity consumed by households in the Europe region, which was 1091 TWh in 2015 [39]. This share, which is sensitive to the parameters estimated/assumed above, is very close to the estimate given by [19]. Recall that Russia is included in this region and needs less electricity for cooling. Moreover, the annual specific cooling electricity demand is found equal to 17.72 $\mathrm{kWh} / \mathrm{m}^{2}$, which is very close to a weighted average of SCE's given in [59] for EU-28 countries, if the populations are used as weightings, i.e. 17.82 .

Regarding (12), for about $324=(1-0.116) \times 366$ million employees, each occupying about 30 square meters of working space on average [19], and by setting the adjustment ratio in (12) to 1.3, the cooling electricity demand for the commercial buildings is estimated at about $225 \mathrm{TWh}$ /year, which means 23.2 $\mathrm{kWh} / \mathrm{m}^{2}$. Reminding again that Russia is also included, this amount of specific electricity consumption is 
comparable with what can be deduced by [21], i.e. $27.7 \mathrm{kWh} / \mathrm{m}^{2}$. This way, verification of (12) is completed, which yields $E_{\mathrm{EU}}=376 \mathrm{TWh}$ /year, i.e. equal to $8.5 \%$ of the total electricity consumption by the region in 2015.

At the final stage, based on the following parameters [62][42]:

- Transmission and distribution system loss [62][42]: 7\%

- Average efficiency for fossil fuel electricity generation [40]: 40\%

- Share of fossil fuel in electricity generation [41]: 52\%

One can easily find that $\eta_{k}=(1-0.07) \times 0.4=0.372$, and:

$F_{\text {EU }}=526[\mathrm{TWh} /$ year $]$.

Finally, given that coal, natural gas and oil products take part in electricity generation by $47.9 \%, 45.7 \%$ and $6.4 \%$ shares respectively, burning this combination of fossil fuel releases about 0.285 kilograms $\mathrm{CO}_{2}$ per $\mathrm{kWh}$ of fossil fuels [41], equivalent to about $0.4 \mathrm{~kg} / \mathrm{kWh}$ GHG for electricity generation [42],[67] [65]. This is calculated by a weighted average between different emission factors for fuels and GHGs. It translates to the emission of $150 \mathrm{k}$-tonnes a year to keep the temperature of all living spaces convenient for people with air conditioners in the Europe area. This amount is $2.6 \%$ of the total amount of $5676 \mathrm{k}$ tonnes emitted due to electricity consumption by all sectors of the region in 2014 [42]. Knowing that the relations are nonlinear, a simple sensitivity calculation can deduce that the emission of $\mathrm{CO}_{2}$ for cooling in summers of this region is between 26 and $27 \mathrm{k}$-tonnes per degree.

The same calculation procedure is implemented for all other 11 regions similarly, the data of which are summarized in Table 2, along with the final results. It should be mentioned that the collection of data for all regions is not an easy task and many estimations should be made to accomplish the procedure. For instance, finding numbers for homeless people, people living in slums or urban habitats around the world, particularly for Asian and African countries is so difficult, costly, cumbersome and time-consuming. This had to be followed searching many different websites such as [63], [64], [65], and [66].

However, the electrical energy demand for the convenience of human beings in summers, all over the world, is estimated by aggregating the values of all groups; that is 2662 TWh, resulting in more than 1558 k-tonnes of $\mathrm{CO}_{2}$, i.e. around $4.5 \%$ of the global emission of $\mathrm{CO}_{2}$ in 2014 [62][42]. Similarly, the total global emission to make buildings temperature convenient for people living indoors is somewhat between 240 and $246 \mathrm{k}$-tonnes of $\mathrm{CO}_{2}$ per one degree of global warming. It means that if the average global temperature increases by one degree, then around $243 \mathrm{k}$-tonnes of more $\mathrm{CO}_{2}$ will be emitted into the atmosphere; i.e. ten folds of what the Europe and Russia region emits. This number will be used for simulation in the next section. 
Table 2: Fossil energy needed for cooling using consumption indices in each region

\begin{tabular}{|c|c|c|c|c|c|c|c|c|c|c|c|c|}
\hline Region & Index & $\begin{array}{l}\text { Living space } \\
\text { per } \\
\text { household } \\
{\left[\mathrm{m}^{2}\right]}\end{array}$ & $\begin{array}{c}\text { Houses with } \\
\text { coolers } \\
\text { [million] }\end{array}$ & $\begin{array}{c}\text { Degree- } \\
\text { hours per } \\
\text { year } \\
{\left[{ }^{\circ} \mathrm{C} \text {-hours] }\right.}\end{array}$ & $\begin{array}{l}\text { Share of } \\
\text { cooling in } \\
\text { residential } \\
\text { electricity }\end{array}$ & $\begin{array}{c}\text { Residential } \\
\text { space } \\
\text { annual } \\
\text { cooling } \\
\text { electricity } \\
\text { [kWh/m2] }\end{array}$ & $\begin{array}{l}\text { Working } \\
\text { space } \\
\text { annual } \\
\text { cooling } \\
\text { electricity } \\
{\left[\mathrm{kWh} / \mathrm{m}^{2}\right]}\end{array}$ & $\begin{array}{c}\text { Fossil fuel } \\
\text { share in } \\
\text { electricity } \\
\text { generation } \\
\text { [\%] }\end{array}$ & $\begin{array}{c}\text { Annual } \\
\text { fossil fuel } \\
\text { consumed } \\
\text { [TWh/year] }\end{array}$ & $\begin{array}{c}\text { Average } \\
\mathrm{CO}_{2} \\
\text { emission for } \\
\text { power } \\
\text { generation } \\
\text { [gr/ } / \mathrm{kWh}]\end{array}$ & $\begin{array}{c}\text { Total } \mathrm{CO}_{2} \\
\text { emission for } \\
\text { cooling } \\
\text { [kT/year] }\end{array}$ & $\begin{array}{c}\text { Share in } \\
\text { total } \mathrm{CO}_{2} \\
\text { emission } \\
{[\%]} \\
{[42]}\end{array}$ \\
\hline \multirow{2}{*}{ North America } & USA & 205 & 105.6 & 8775 & 18.0 & 29.9 & 37.4 & 68 & 773 & 309 & \multirow{2}{*}{241} & \multirow{2}{*}{4.2} \\
\hline & Canada & 186 & 7.7 & 2160 & 0.9 & 7.5 & 9.8 & 20 & 5.8 & 315 & & \\
\hline \multicolumn{2}{|c|}{ Europe } & 104 & 184.6 & 4400 & 13.5 & 17.7 & 23.2 & 52 & 519 & 285 & 148 & 2.6 \\
\hline \multicolumn{2}{|c|}{ Oceana } & 217 & 6.7 & 7800 & 17.5 & 26.3 & 32.9 & 90 & 76.2 & 339 & 26 & 4.1 \\
\hline \multirow{5}{*}{ Asia } & East Asia & 94 & 174.1 & 5445 & 16.2 & 23.9 & 28.7 & 80 & 1219 & 321 & 391 & 3.2 \\
\hline & South Asia & 98 & 30.2 & 10150 & 14.7 & 58.5 & 65.5 & 81 & 954 & 264 & 252 & 9.7 \\
\hline & South East & 94 & 27.1 & 9800 & 13.7 & 53.9 & 60.4 & 76 & 440 & 291 & 128 & 9.2 \\
\hline & Central Asia & 123 & 4.9 & 3850 & 13.1 & 19.8 & 23.7 & 85 & 45.9 & 250 & \multirow{2}{*}{188} & \multirow{2}{*}{6.4} \\
\hline & Middle East & 176 & 33.6 & 12400 & 23.6 & 57.7 & 69.2 & 96 & 743 & 238 & & \\
\hline \multirow{2}{*}{ Africa } & North Africa & 111 & 8.7 & 12000 & 26.9 & 70.9 & 78.0 & 93 & 200 & 218 & \multirow{2}{*}{86} & \multirow{2}{*}{6.5} \\
\hline & Sub-Saharan & 107 & 15.3 & 12250 & 18.3 & 63.7 & 70.0 & 64 & 168 & 251 & & \\
\hline \multicolumn{2}{|c|}{ Latin America } & 140 & 34.2 & 9100 & 26.8 & 39.4 & 47.3 & 50 & 390 & 249 & 97 & 5.1 \\
\hline \multicolumn{2}{|c|}{ Average } & 138 & - & 8094 & - & 39.1 & 48.90 & 71.3 & - & 278 & - & - \\
\hline \multicolumn{2}{|c|}{ World } & - & 630.1 & - & 17.0 & 12.6 & 41.5 & 69.6 & 5534 & - & 1558 & 34463 \\
\hline
\end{tabular}




\section{Loop gain and long-term evolution estimates}

Evidently, there are complexities and nonlinearities between GHG (carbon dioxide) concentration and the average global temperature referred to by the pioneers [2]. There are very sophisticated almost complete models that can simulate climatic changes [67] or calculate GHG emissions. There are estimates on the total effect of $\mathrm{CO}_{2}$ concentration on the temperature that range from (1.5-4.5) ${ }^{\circ} \mathrm{C}$ for doubled carbon volume in the atmosphere, where no feedback effect is considered [68], to $11.5^{\circ} \mathrm{C}$, if the feedback effects are also simulated [3]. In the literature, there are attempts to estimate the parameters using a general simplified system of differential equations as follows:

$$
\begin{aligned}
\dot{V} & =f(V, \theta) \\
\dot{\theta} & =g(V, \theta)
\end{aligned}
$$

where $V$ and $\theta$, as state variables, denote GHG volume in the atmosphere and its average temperature, respectively. For instance, a linear equation for $f(V, \theta)=0$ and a logarithmic one for $g(V, \theta)=0$ are assumed by [69] to estimate the equilibrium lines. Then, historical data series are applied to estimate the probable equilibrium displacement due to anthropogenic emissions. However, relying on that the more decomposed is an analysis, the more accurate will be the results, the present research merely aims the feedback impact of a single loop made by cooling systems. In this regard, the following two differential equations simply describe the dynamics of carbon emission and the other GHGs due to the electricity generation/consumption for cooling in summers:

$$
\begin{aligned}
\dot{V} & =u_{G}(t)+f(\theta) \\
\dot{\theta} & =g(V)
\end{aligned}
$$

Herein, $f(\theta)$ and $u_{\mathrm{G}}(t)$ represent GHG emission by cooling electricity generation and all the other resources, respectively. Temperature increase caused by GHG concentration is shown by $g(V)$ in the second equation. Regardless of sophisticated models, and thinking of a simplified linear model, we focus on the estimation of a loop gain at a snapshot, i.e. by freezing the time at the current moment.

Based on the results obtained in the last section, a linear approximation can be substituted for $f(\theta)$ in (23) resulting in:

$$
\Delta V=\Delta u_{\mathrm{G}}(t)+\tau \Delta \theta
$$

with $\tau=240 \mathrm{k}$-tonnes per ${ }^{\circ} \mathrm{C}$; i.e. a single degree increase in the average temperature around 
living/working spaces in summer days of each year will cause about $240 \mathrm{k}$-tonnes of GHG for cooling those spaces, in addition to $\Delta u_{\mathrm{G}}$ emitted from all other resources of GHG.

\subsection{Linearization and approximate relationships}

One may linearize (24) by the first two terms of the Taylor series around a fictitious point, $\left(V_{0}, \theta_{0}\right)$, as follows:

$$
\theta=\theta_{0}+g_{0} \cdot\left(V-V_{0}\right)
$$

where $\theta_{0}$ is assumed to be an equilibrium value equal to zero, and $g_{0}=\left.\frac{\partial g}{\partial V}\right|_{V_{0}}$ is the slope of a tangent line. Assuming a linear relationship between concentrations of $\mathrm{CO}_{2}$ in the atmosphere and the average temperature, replaced for (24), we must estimate an almost constant slope (a steadystate ratio), say $\kappa$, to relate annual changes in the temperature anomaly, denoted by $\Delta \theta^{*}$, to the annual carbon dioxide emission in the world:

$$
\Delta \theta^{*}=\kappa \Delta V .
$$

Let us name $\kappa$ by warming coefficient. Both simulations results made by climate-carbon models and linearized approximations reported by researchers indicate that for every trillion tonnes of carbon $(\mathrm{TtC})$ emitted to the atmosphere temperature rise would be between 1.0 and $2.1^{\circ} \mathrm{C}$ [70]. It is noteworthy that research reveals that the proportionality has been historically steady between global temperature change and cumulative $\mathrm{CO}_{2}$ emissions for hundreds of years [71]. Moreover, recent works mention that the relationship is nonlinear during periods of net negative emissions. In fact a hysteresis-like relation appears when a negative emission starts due to a lag in ocean response, and then an almost linear relation shows up again [71].

However, statistics show that the anomaly on the land surface has started to increase noticeably faster than the global anomaly since the 1980s. Figure 6 demonstrates how the temperature anomaly has been increasing during the last century, where we can clearly observe a distinction between the two signals. By sketching statistical data of land surface anomaly since 1960 to 2016 versus cumulative CE, CCE (Figure 7), one may test if linearization can be successfully applied to describe the relationships. The linear curves fitted to data indicate that (26), and consequently (27), are acceptable approximations, where $\kappa=g_{0} \approx 0.0074\left[{ }^{\circ} \mathrm{C} / \mathrm{GtC}\right]$. This implies that the coefficient is more than three times of what reported for the global temperature anomaly changes versus carbon emission. To be a bit conservative, the coefficient may be assumed $\kappa \approx 0.0035\left[{ }^{\circ} \mathrm{C} / \mathrm{GtC}\right]$ in this paper. 


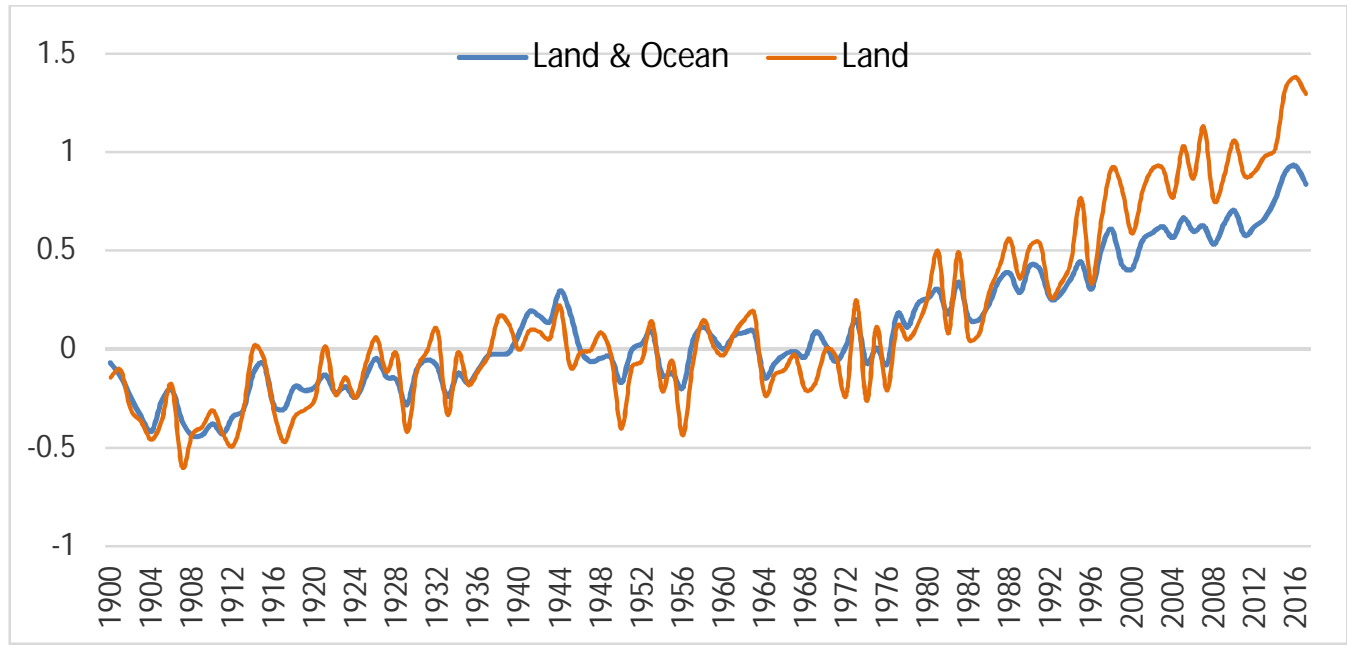

Figure 6: Temperature Anomaly, $\theta^{*}$

Data Source: National Oceanic and Atmospheric Administration: http://www.ncdc.noaa.gov/cag/timeseries/global [72]

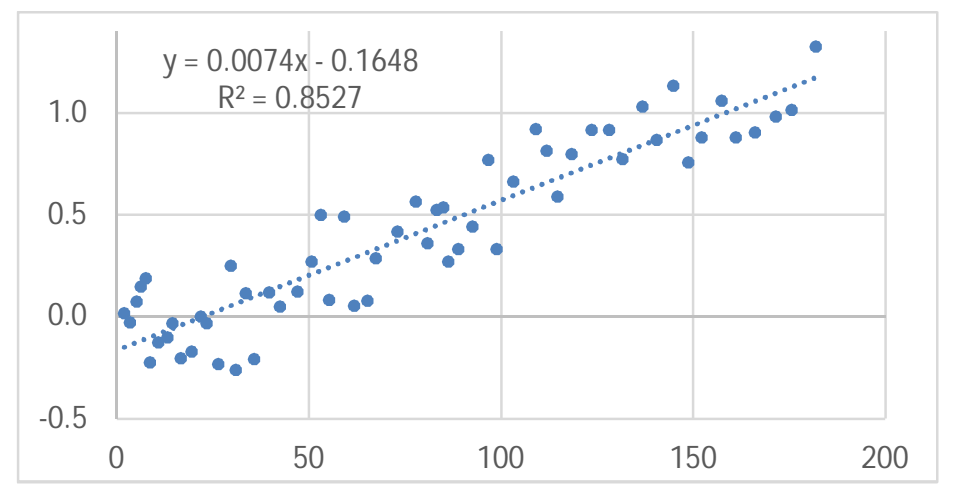

Figure 7: Average Land Temperature Anomaly, $\theta^{*}$ versus Cumulative Carbon Emission [GtC]

In order to achieve more confidence, we apply a simple one-variable time series model on the smoothed variation of temperature anomaly, $\Delta \theta^{*}$, which is depicted in Figure 8. The two signals in the figure are outputs of the two following smoothing filters.

1) A moving average (MA) smoothing filter $(m=n=2)$ :

$y(t)=\operatorname{MA}\{x(t)\}=\frac{1}{m+n+1} \sum_{i=-m}^{n} x(t+i)$,

2) A single-rule fuzzy smoothing filter (FS) represented by the following symbol [73]: $y(t)=F S\{x(t)\}$.

The oscillation pattern due to the sunspots' cycles with periods between 8 and 14 years (11 years on average) is clearly recognizable. Obviously, there is also a random component which is probably caused by the amount of $\mathrm{CO}_{2}$ absorbed by oceans [12]; however, modeling of those parts of the signal by distinct exogenous variables are not aimed in this research for the sake of 
simplicity. There are other multi-variant models that employ several variables other than carbon emission [74].

The corresponding power spectrum of $\Delta \theta^{*}$ is estimated by a simple FFT $^{\ddagger}$ algorithm and the result is shown in Figure 9. Although derivative of the anomaly was approximately integrated to zero by the middle of the century, it exhibits an obvious trend for after the 1950s, the slope of which is gradually shifting to higher tilts in recent decades. Therefore, we would prefer to choose data from the recent 61 years for estimation of the warming coefficient, $\kappa$, in (27), or $g_{0}$ in (26). To do so, several $(p, q)$-order autoregressive (AR) models with a first order moving average (MA) model on the error term are chosen to be applied (See the Appendix: ARMAX models):

$$
y(t)=\alpha_{0}+\sum_{i=1}^{p} \alpha_{i} y(t-i)+\sum_{j=1}^{q} \kappa_{j} u(t-j+1)+\sum_{k=0}^{1} \varepsilon_{k} e(t-k)
$$

where $\alpha_{0}$ is the intercept, $\alpha_{i}$ 's, $\varepsilon_{k}$ 's and $\kappa_{j}$ 's are unknown coefficients, the extra input $(\mathrm{X}), u(t)$ is replaced with the $\mathrm{CE}$ or $\mathrm{CCE}$, and $e(t)$ is a normal white noise. The dependent variable $y(t)$ maybe either change in the land temperature anomaly, $\Delta \theta^{*}$, or $\theta^{*}$ itself. In both cases, the signals can be smoothed by (29). Indeed, we could regress the land temperature anomaly on the atmospheric growth of carbon, since these two have higher correlations. However, since it is not known how much of the emitted carbon for cooling is absorbed by land or oceans, only the total amount participates in the model. Figure 10 shows the trend in $u(t)$, i.e. the total global carbon emission, along with the carbon's atmospheric growth variations [75], [76].

Depending on the definition of $y(t), g_{0}$ or $\kappa$ would be estimated by the DC-gain from $u(t)$ to $y(t)$, i.e. global land temperature anomaly, as follows:

$$
\kappa=\lim _{z \rightarrow 1} \frac{\sum_{j=1}^{q} \kappa_{j} z^{-1}}{1-\sum_{i=1}^{p} \alpha_{i} z^{-1}}
$$

Among from all cases that (30) could be built by various combinations of the input and output, the results are reported just for $y(t)=\mathrm{CE}$ and $u(t)=F S\left\{\Delta \theta^{*}(t)\right\}$, which won the competition between all models [77]. Table 3 includes a summary result of the estimates on $\kappa$, varying with $(p$, $q$ ), the dynamic orders of the ARMAX model, and with various data sets defined by different starting year.

\footnotetext{
\# Fast Fourier Transform
} 


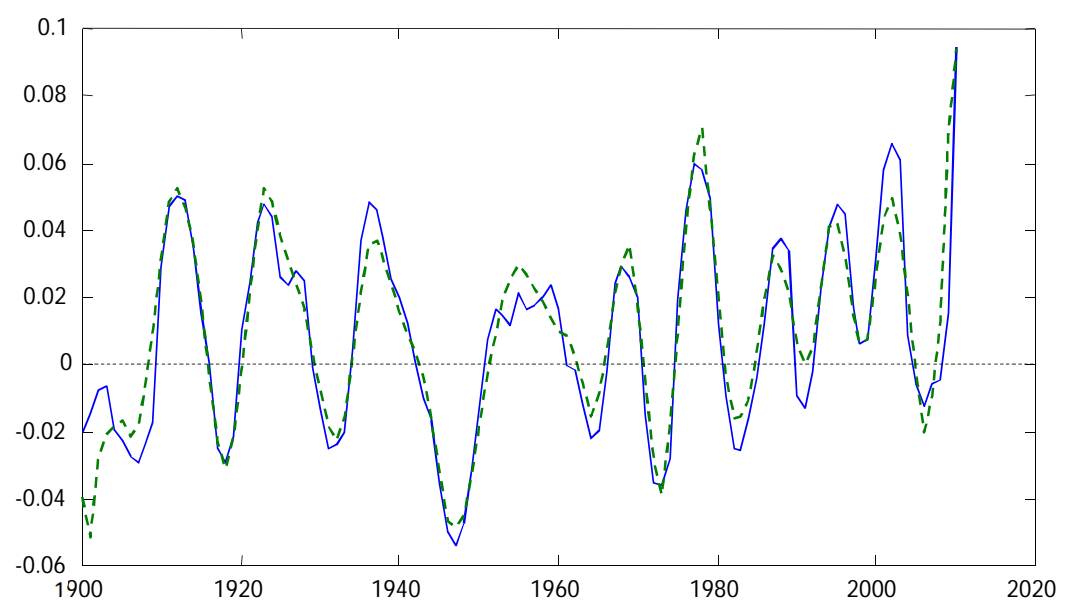

Figure 8: Difference in Temperature Anomaly, $\Delta \theta^{*}\left[{ }^{\circ} \mathrm{C}\right]$, smoothed by both moving average (solid line) and fuzzy smoothing (dashed line)

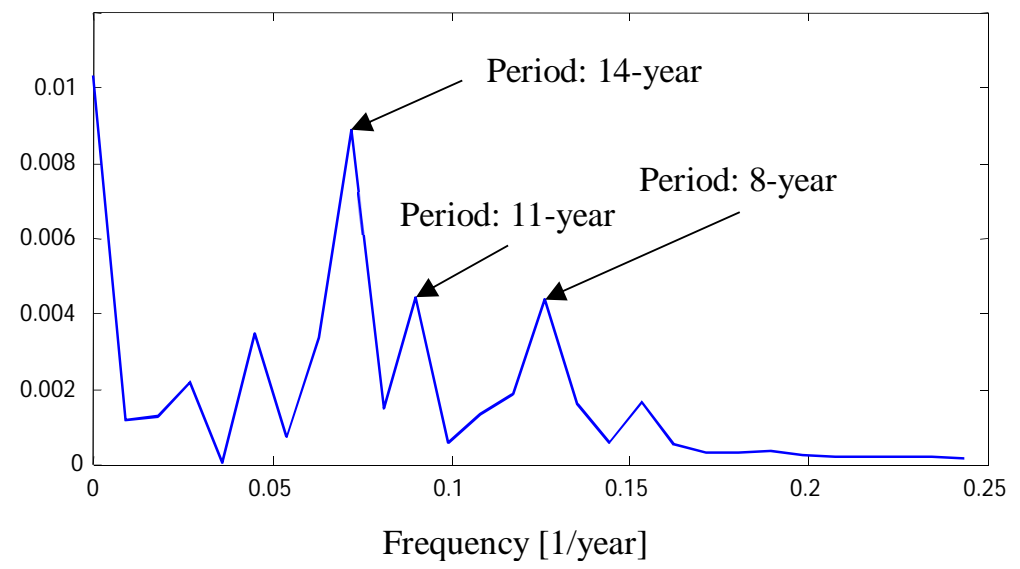

Figure 9: Power spectrum of smoothed $\Delta \theta^{*}$; the high-frequency oscillations are filtered.

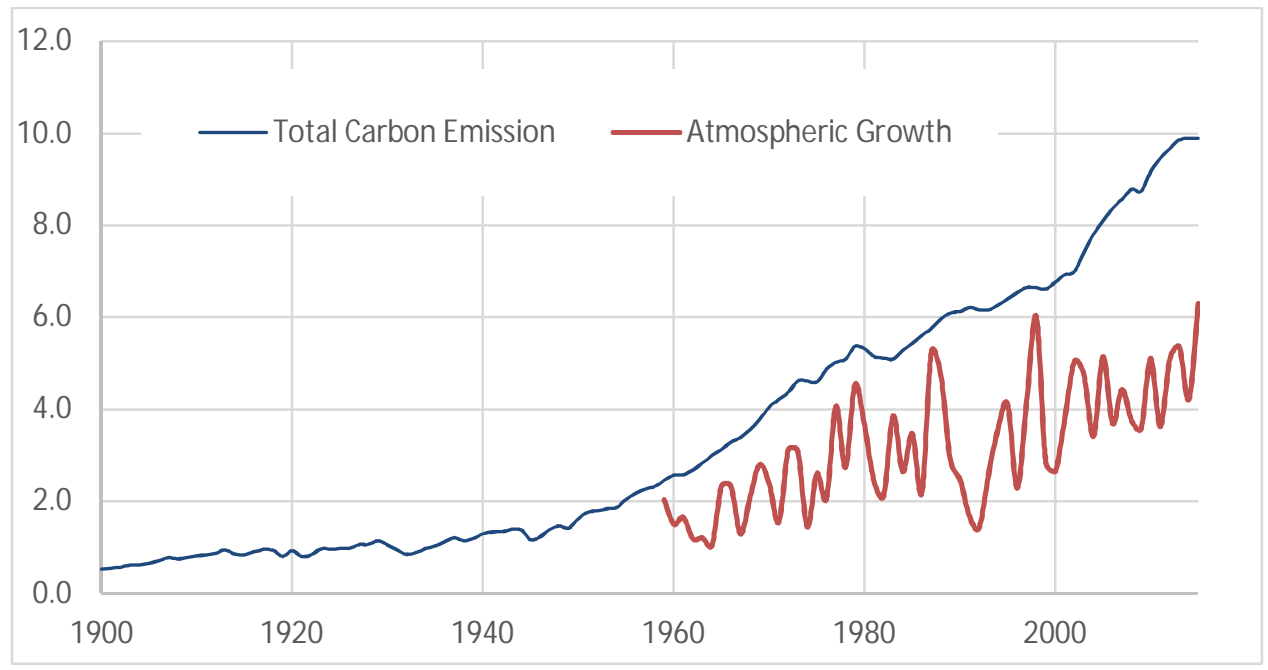

Figure 10: Carbon emission trend (billion metric tons of carbon per year)

Data Source: The Global Carbon Budget, 2016 [75], [76]. 
Here are more details on the table content. The results obtained based on three sets of data samples picked up amongst data given in Figure 10 indicate that $\kappa$ is in line with the static estimate, but perhaps decreasing. For further clarification, $\kappa\left(t_{0} ; p, q\right)$ is estimated by setting $t_{0}=1960$ (when anomaly was approximately zero), 1970, 1980; $p=2, \ldots, 9$, and $q=1, \ldots, 7$. This means $3 \times 8 \times$ $7=168$ parallel models participate in a competition. Then, the estimated models are sorted based on a utility proxy computed via the model selection method introduced in [77]. The first three models for each of the three data sets are given in the table. It is important to emphasize that ranking of the models is based on fourteen various characteristics including the adjusted explanatory coefficients, $\overline{\mathrm{R}}^{2}$, the randomness of residuals, significance and dynamic properties of the estimated parameters, etc.

Table 3: Estimates of the warming coefficient, $\kappa\left(t_{0} ; p, q\right)\left[{ }^{\circ} \mathrm{C} / \mathrm{TtC}\right]$

\begin{tabular}{|c|c|c|c|c|c|c|c|c|}
\hline \multirow{2}{*}{$\frac{\text { Data Set }}{(p, q)}$} & \multicolumn{2}{|c|}{$1960-2015\left(t_{0}=1960\right)$} & \multirow[b]{2}{*}{$(p, q)$} & \multicolumn{2}{|c|}{$1970-2015$} & \multirow[b]{2}{*}{$(p, q)$} & \multicolumn{2}{|c|}{$1980-2015$} \\
\hline & Utility & $\kappa$ & & Utility & $\kappa$ & & Utility & $\kappa$ \\
\hline$(5,1)$ & 0.857 & 6.20 & $(3,1)$ & 0.919 & 5.83 & $(3,1)$ & 0.865 & 5.87 \\
\hline$(2,2)$ & 0.857 & 9.96 & $(2,2)$ & 0.859 & 4.53 & $(2,2)$ & 0.854 & 5.04 \\
\hline$(2,1)$ & 0.832 & 9.68 & $(2,1)$ & 0.844 & 3.44 & $(3,2)$ & 0.851 & 4.59 \\
\hline $\begin{array}{c}\text { Weighted } \\
\text { Average } \\
\bar{\kappa}\left(t_{0}\right)\end{array}$ & \multicolumn{2}{|c|}{7.267} & & \multicolumn{2}{|c|}{4.363} & & \multicolumn{2}{|c|}{5.283} \\
\hline
\end{tabular}

The oscillations period derived from the roots of AR part of the best winning models varies between 6.8 to 14 years, mostly centered around eight years. This confirms that the global climatic conditions are oscillating with this period (See Figure 9). The best dynamics found showed that higher order models would not result in more accurate models, and orders between $p=2$ and $p=5$ have led to the most optimum models.

The table also contains weighted average values, applying the overall utility value of the models as weightings:

$$
\bar{\kappa}\left(t_{0}\right)=\frac{\sum_{p, q}^{N p, q} U\left(t_{0} ; p, q\right) . \kappa\left(t_{0} ; p, q\right)}{\sum_{p, q}^{N p, q} U\left(t_{0} ; p, q\right)},
$$

where $U($.$) denotes the Utility concerning each estimated \kappa$, and $N_{p, q}=12$. Based on the best results obtained for each data set, similar calculations are replicated for:

$$
(p, q)=\{(2,1),(3,1),(5,1),(2,2),(3,2),(5,2)\}
$$

i.e. the dynamics with higher utilities on average, leading to time-varying $\kappa(t)$ 's, where $t$ is the starting date of the chosen data set. Because of the increasing uncertainty, the values obtained for 
$t_{0}>1995$ are omitted to avoid over-parameterized models, with low statistics, e.g. $t$-student and $\overline{\mathrm{R}}^{2}$. It is seen in Figure 11 that the warming rate, $\kappa$, was almost constant and lower before the energy boost era after the second war. The increasing $\kappa(t)$ in $1970-1985$ indicates an acceleration of global warming. Although with lower utility and higher uncertainty, fortunately, the coefficient estimated for the last few years has a falling trend, but its behavior in these years is under a big question due to its variance, which has signs of future increase.

Based on the best regressions, $\kappa$, as a factor of global warming acceleration, has experienced a persistent growth (hitting its highest values in 1985 to 1987) after the Second World War, for fast industrial development by widely burning fossil fuels. It seems that thereafter, technological progress has gradually helped to control the speed of $\mathrm{CO}_{2}$ emission growth. However, referring to Figure 8 and Figure 10, the recent decade witnessed again a rising period with oscillations. Yet, there are not enough data samples to apply higher order models in the form of (30) to estimate the coefficient for the last two decades. The spreading $16^{\text {th }}$ to $84^{\text {th }}$ percentiles in Figure 11 reveals that the uncertainty is more than that one can assure about the future of the coefficient.

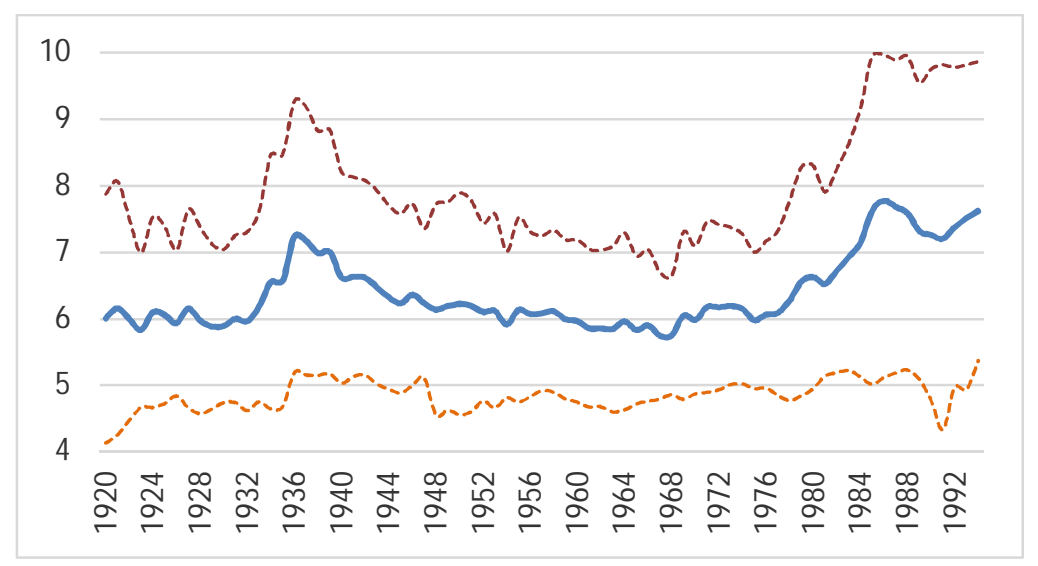

Figure 11: Variation in the average values (and $\mu \pm \sigma$ ) of $\kappa(t)\left[{ }^{\circ} \mathrm{C} / \mathrm{TtC}\right]$ based on the six models as a function of the starting date of the data set

In summary, the results indicate about 4.3 to $7.2{ }^{\circ} \mathrm{C}$ increase in the average land temperature per terra tons of additional carbon emitted each year by fossil fuel consumption in the world. It is noteworthy that DC-gain refers to a long-term effect (unlike an instant effect) of an input to a system. As a pessimistic average, and regarding the slope obtained in Figure 7, let's take it equal to $6{ }^{\circ} \mathrm{C} / \mathrm{TtC}$; thus, according to $(27)$ it is estimated that the $1558 \mathrm{kt}$ of additional $\mathrm{CO}_{2}$ in the atmosphere for cooling (see Table 2) in a year will cause:

$\Delta \theta=\kappa \Delta V=\left(6 \times 10^{-12}\right)\left[{ }^{\circ} \mathrm{C} /\right.$ tonne $] \times\left(1558 / 3.667^{\S}\right) \times 10^{3}$ [tonne $]=2.55 \times 10^{-6}{ }^{\circ} \mathrm{C}$ warmer land

\footnotetext{
$\S$ It should be mentioned that one metric ton of carbon is equivalent to 3.667 metric tons of $\mathrm{CO}_{2}[75]$.
} 
temperature in the next year, just for cooling of buildings. Combining (25) and (27), which simplify the cooling positive loop in Figure 2 to Figure 12, it means a loop gain equal to:

$1+6\left[{ }^{\circ} \mathrm{C} / \mathrm{TtC}\right.$ tonne $] \times 240\left[\right.$ kilo tonne $\left./{ }^{\circ} \mathrm{C}\right]=1.0000014$.

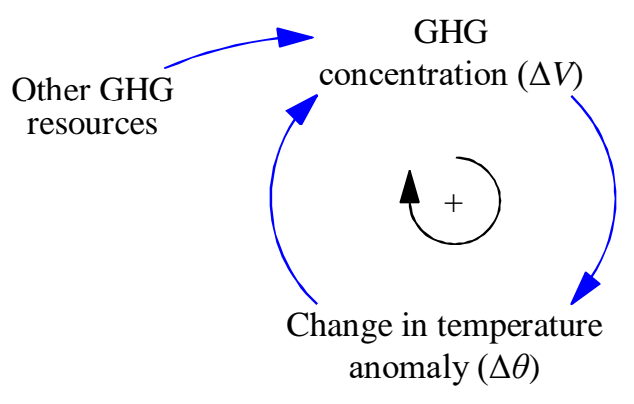

Figure 12: Simplified cooling positive loop

Although this number seems a tiny one, the point is being grated than one which means a positive, and so, reinforcing loop. It is noticeable that due to (25) the total emission of $\Delta V=36.79$ Gigatonnes, emitted by all the GHG resources in 2017 [75], warmed up the average global land temperature by:

$\kappa \Delta V=6\left[{ }^{\circ} \mathrm{C}\right.$ per $\left.\mathrm{TtC}\right] \times(36.79 / 3.667) \times 10^{9}[$ tonne $]=6.0 \times 10^{-2}\left[{ }^{\circ} \mathrm{C}\right]$, which is not a small amount for an annual increment of the global temperature anomaly. Accordingly, such an increase has led to $240\left[\mathrm{k}\right.$-tonnes $\left./{ }^{\circ} \mathrm{C}\right] \times 6.0 \times 10^{-2}\left[{ }^{\circ} \mathrm{C}\right]=14.4 \mathrm{k}$-tonnes more carbon dioxide in the next year to cool buildings.

\subsection{Simulation results of temperature anomaly}

Many valuable works that have summarized different forecasts of future global warming are published. However, there are too many uncertainties to provide a reliable prediction of the climatic responses to the anthropogenic GHG emission changes [3]. Among many, two are referred to hereby, which exclude feedbacks. Under different scenarios, it is estimated that until 2100 the globe will be warmed up to at least $1.5^{\circ} \mathrm{C}$, in the best scenario, and above $4.5^{\circ} \mathrm{C}$, hitting $6.1^{\circ} \mathrm{C}$, even more, in the worst cases, with different probabilities [78], [79].

In this section, ignoring the short-term oscillations in the temperature anomaly, and based on the above mentioned simple linear approximation model, (25) and (27) are used for simulation towards the end of the current century. Figure 13 shows the simulation results for two scenarios. 

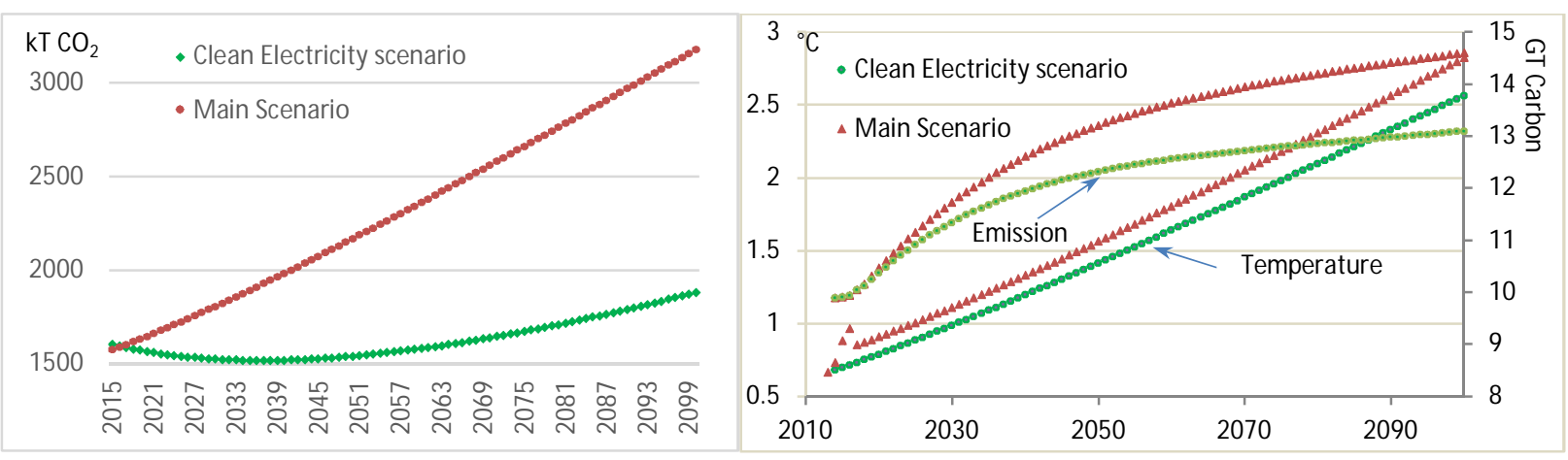

Figure 13: Simulation results for the average global anomaly $\left[{ }^{\circ} \mathrm{C}\right]$ along with carbon emission [GtC/yr] (right), and projection of $\mathrm{CO}_{2}$ emission [kt/yr] from cooling (left); main scenario (low emission growth), and the clean energy scenario.

Noting that the emission from cooling electricity is a very minor part of $\Delta V(t)$ in (25), for the first scenario (low growth) it is assumed that the growth in $\mathrm{CO}_{2}$ emission starting from $\Delta u_{\mathrm{G}}(t=2017)$ $=3.68 \times 10^{10}$ tonnes $(\approx 10 \mathrm{GtC})$ is $1.6 \%$, which is the average growth rate of the last decade. Then, annual mitigation by $5 \%$ will reduce it to about $0.1 \%$ by the end of the century. In a second scenario it is assumed that the $30.4 \%$ of electricity generation by non-fossil fuels (see Table 2 last row) can increase by $1 \%$ from 2018 ahead, reaching $60 \%$ by the end of the century, while its growth rate will be falling by $0.03 \%$ annually ${ }^{* *}$ (See the negative loop marked in Figure 3 ). This way, although the annual growth rate of carbon emission will be less than $1 \%$, based on a rough assumption that half of the emission is absorbed by either oceans or the lands (i.e. the average ratio since 1990), the global concentration of carbon will reach to almost 5200 Gigatonnes of $\mathrm{CO}_{2}$ (equivalent to $1420 \mathrm{GtC}$ or $666 \mathrm{ppm}$ ) by the end of the century. This is very close to the projections made by the Intergovernmental Panel on Climate Change (IPCC), under the most optimistic scenarios [68]. Apparently, if the positive feedbacks from other loops are included, higher rates would be achieved [80].

Consequently, the global average (ocean and land) temperature anomaly will increase from about $0.8{ }^{\circ} \mathrm{C}$ in 2017 to more than $2.8^{\circ} \mathrm{C}$ in 2100 . The warming is accelerated by about $2 \%$ a year at the beginning of the simulation period. Based on the above assumptions, this will fall gradually to make an average of around $1 \%$ a year until the end of the century. This is also the same as the results of A1B and B2 scenarios in IPPC reports. However, based on the A1FI (fossil-intensive) scenario, the global average temperature may increase by about $4{ }^{\circ} \mathrm{C}$ [68], even exceed it hitting 5

\footnotetext{
** Although the past trends were stalled in 2015, and IEA reports show flatness of emission from energy sector for third straight year, new reports indicate that global $\mathrm{CO}_{2}$ emission (including all sectors) set to rise $2 \%$ in 2017, mostly caused by coal consumption in China (https://insideclimatenews.org).
} 
${ }^{\circ} \mathrm{C}$ (median) [78], [79]. Nevertheless, by applying $\kappa=6\left[{ }^{\circ} \mathrm{C} / \mathrm{TtC}\right]$, the land temperature which will be perceived by building residents may pass $7{ }^{\circ} \mathrm{C}$ at the end of the century. Hence, in the main scenario (low growth) emission from cooling electricity hits 3174 k-tonnes, which causes approximately an extra $0.002{ }^{\circ} \mathrm{C}$ increase per year.

The figure also contains results for the "clean energy" scenario, where emission will optimistically limit to $13 \mathrm{GtC}$ finally leading to less than $2.6^{\circ} \mathrm{C}$. Since the amount of emission from the cooling loop is ignorable compared to the emissions from other sources, there won't be a remarkable change in the temperature anomaly; however, the emissions from this loop will drop to around $1500 \mathrm{k}$-tonnes, and then the positive reinforcing loop will bring the growth back to almost the same speed as the main scenario, although the total emission will be gradually stalling.

Electricity generation holds about $16 \%$ of the total energy production in the world and the sector is responsible for about $12 \%$ of $\mathrm{CO}_{2}$ emissions. These ratios are much more for OECD countries [81]. Thus, in the second scenario, the global emission may reduce by $10 \%$ at most, which doesn't sound a solemn solution for the serious problem of global warming. Whilst, because of the electrification growth, it is expected that within the rest of the century the energy sector burns more fossil fuel for electricity generation.

\section{Conclusion and remarks}

There are many causes that are making the globe warmer every year. Many of these causes are positively activating closed loops, known as "snowball effect", which accelerate the changes over time. Since a complex system is better analyzed and understood if its components are separately analyzed first, one of those positive loops is studied in this research. A bottom-up spread-sheet model is developed to estimate cooling electricity load for 12 regions all around the world. The load is formulated so that is related to the temperature variations in summer. This way, it can be estimated how much more electricity would be consumed for each centigrade of warmer summers. Then, fossil fuel shares in electricity generation are used to estimate the amount of $\mathrm{GHG}\left(\mathrm{CO}_{2}\right.$ equivalent) emission, and to find out how much more GHG would be released in the atmosphere per unit of global warming. The estimates show that at the current conditions, almost $240 \mathrm{k}$-tonnes of more GHG would be emitted for cooling per each centigrade of warmer summers.

On the other hand, by means of parallel ARMAX models, which are fed by historical data of carbon-equivalent emissions and temperature anomaly. The coefficient by which the average land temperature would increase per each unit of GHG emissions is then estimated based on the model 
DC-gain. It is concluded that each Gigatonne of GHG would cause about $0.006{ }^{\circ} \mathrm{C}$ higher temperature anomaly perceived over lands. Hence, the cooling positive loop currently would have a loop gain of about 1.0000014 .

Although the loop-gain sounds to be ineffective on the acceleration of global warming, the system is nonlinear and so the number would increase fast. Indeed, interconnected positive closed loops in Figure 1 may lead to very faster warming. Therefore, it is highly recommended to extend the current efforts as much as possible to reduce this gain by renewable energies as shown in Figure 3. Future studies may focus on the other side of the system to assess how much the lowered heating in winters can compensate this positive loop, or how much the fluctuations caused by a wild jet stream pattern that has led to colder winters and hotter summers can deteriorate the situation.

Many scientific reports have addressed the climatic changes caused by natural and/or anthropogenic carbon emissions, few have considered feedback effects [3], [69]. A complete model is required that connects all subsystems and includes all loops to conclude with higher certainty; however, the numbers indicating current growth rates of the factors worsening the case imply that the currently ongoing solutions are not promising, and other effective alternatives should be considered by the world society. It would be striking to remind that East Asia, North America, and Europe are responsible for $34 \%, 18 \%$, and $17 \%$ of $\mathrm{CO}_{2}$ emission and so the global warming problem, respectively [81]. Thus, the world community expects these majorities to establish applicable solutions before reaching the irreversible point.

\section{Acknowledgment}

The author is so thankful of the valuable comments of Dr. B. Sajadi, assistant professor at the School of Mechanical Engineering, University of Tehran, as well as the efforts made by H. Zaman, graduate student at Department of Management Sciences and Quantitative Methods, Montreal, Canada, in collection of some parts of data required for the calculations. He is also very thankful for the anonymous reviewers whose valuable comments helped a lot in the improvement of the authenticity of this paper. This research was partially granted by the University of Tehran under grant number 8109923/1/10; however, the accuracy of the results may be further improved if it is supported by an international institute. 


\section{References}

[1] Mitchell, J.F.B.; C.A. Senior and W.J. Ingram (1989). CO2 and climate: a missing feedback? Letters to Nature, Nature, September 1989; 341: 132-134. Available (accessed April 2019): https://www.nature.com/articles/341132a0

[2] National Research Council (NRC). 2010. Advancing the Science of Climate Change. National Research Council. Washington, DC: The National Academies Press. https://doi.org/10.17226/12782.

[3] Stainforth, D.A.; T. Aina, C. Christensen, M. Collins, N.E. Faull, D.J. Frame, J. Kettleborough, S. Knight, A.P. Martín, J.M. Murphy, C.U. Piani, D. Sexton, L.A. Smith, R.A. Spicer, A.J. Thorpe and M.R. Allen (2005). Uncertainty in predictions of the climate response to rising levels of greenhouse gases. Nature, 2005; 433: 403406. DOI:10.1038/nature03301

[4] Ford, Andrew (2009). System Dynamics Models of Environment, Energy and Climate Change, Encyclopedia of Complexity and Applied Systems Science, 2009. https://doi.org/10.1007/978-1-4419-7701-4_43.

[5] Fiddaman, T. (2002). Exploring Policy Options with a Behavioral Climate-Economy Model, System Dynamics Review, 2002; 18 (2). https://doi.org/10.1002/sdr.241.

[6] IPCC (1996) Climate Change 1995. 3 vols. Cambridge: Cambridge University Press.

[7] Friedlingstein, Pierre; Laurent Bopp, Philippe Ciais, Jean-Louis Dufresne, Laurent Fairhead, Herv’e LeTreut, Patrick Monfray and James Orr (2001). Positive feedback between future climate change and the carbon cycle, Geophysical Research Letters, 2001; 28 (8): 1543-1547. Available at (last accessed April 2019): https://agupubs.onlinelibrary.wiley.com/doi/pdf/10.1029/2000GL012015.

[8] Davidson, Eric A. and Ivan A. Janssens (2006). Temperature sensitivity of soil carbon decomposition and feedbacks to climate change, Nature, 2 March 2006; 440: 165-174. DOI: 10.1038/nature04514.

[9] Laurance, William F. and G. Bruce Williamson (2001). Positive Feedbacks among Forest Fragmentation, Drought, and Climate Change in the Amazon, Conservation Biology, 2001; 15 (6): 1529-1534. Available at (last accessed April 2019): https://www.jstor.org/stable/3061252.

[10] Cox, P.; R. Betts, C. Jones, S. Spall and I. Totterdell (2000). Acceleration of global warming due to carbon-cycle feedbacks in a coupled climate model, Nature, 2000; 408: 184-187. DOI: 10.1038/35041539.

[11] Dufresne, J.L.; P. Friedlingstein, M. Berthelot, L. Bopp, P. Ciais, L. Fairhead, H. Le Treut and P. Monfray (2002). On the magnitude of positive feedback between future climate change and the carbon cycle, Geophysical Research Letters, 2002; Vol. 29 (10): 43-1-4. https://doi.org/10.1029/2001GL013777. 
[12] Global Carbon Project. http://www.globalcarbonproject.org. (Last accessed April 2019)

[13] Th. Franks (2005). Climate change impacts on building heating and cooling energy demand in Switzerland, Energy and Buildings, November 2005, 37 (11): 1175-1185. Available at (Lat accessed April 2019): www.ethz.ch/content/dam/ethz/special-interest/mtec/cepe/cepe-dam/documents/people/baebischer/Aebischer_IEECB_06_paper_9-3-06.pdf

[14] Xu, Peng; Yu Joe Huang, Norman Miller, Nicole Schlegel and Pengyuan Shen (2012). Impacts of climate change on building heating and cooling energy patterns in California, Energy, 2012; 44: $792-804$. doi:10.1016/j.energy.2012.05.013

[15] Wang, Haojie and Qingyan Chen (2014), Impact of climate change heating and cooling energy use in buildingsin the United State, Energy and Buildings, 2014; 82: 428-436.

[16] Vanek, Francis M. and Louis D. Albright (2012). Energy Systems Engineering; Evaluation and Implementation, McGraw Hill. Second Edition: 2012.

[17] Friedlingstein, P.; J. L. Dufresne, P. M. Cox and P. Rayner (2003). How positive is the feedback between climate change and the carbon cycle? Tellus, 2003; 55B: 692-700. https://doi.org/10.1034/j.1600-0889.2003.01461.x.

[18] Capua, Giorgia Di and Dim Coumou (2016). Changes in meandering of the Northern Hemisphere circulation, Environmental Research Letters, 2016:094028. https://doi:10.1088/1748-9326/11/9/094028

[19] Tobias Fleiter, Simon Hirzel, Martin Jakob, Jan Barth, Laura Quandt, Felix Reitze, Felipe Toro, Martin Wietschel (2010). Electricity demand in the European service sector: A detailed bottom-up estimate by sector and by enduse, Improving Energy Efficiency in Commercial Buildings (IEECB) 2010, April 13th-14th, Frankfurt.

[20] EIA Residentional Energy Consumption Survey (2009). https://www.eia.gov/consumption/residential/data/2009/ (Last accessed: April 2019).

[21] Paolo Zangheri, Roberto Armani, Marco Pietrobon and Lorenzo Pagliano (2015). Heating and cooling energy demand and loads for building types in different countries of the EU (eERG). Intelligent Energy Programme of the EU, 2014. http://www.entranze.eu

[22] EIA Residentional Energy Consumption Survey (2015). https://www.eia.gov/consumption/residential/ (Last accessed: April 2019).

[23] Burdick, Arlan (2011). Strategy Guideline: Accurate Heating and Cooling Load Calculations, US DOE, Buildings Technolohies Program, IBACOS, Inc., June 2011. 
[24] Krese, G.; M. Perk, V. Butala, Analysis of Buildings Electric Energy Consumption Data Using an Improved Cooling Degree-Day Method, Journal of Mechanical Engineering, 2012; 58 (2): 107-114.

[25] Shakouri G., H.; R. Nadimi and F. Ghaderi (2009). A hybrid TSK-FR model to study short-term variations of the electricity demand versus the temperature changes, Expert Systems with Applications, 2009; 36 (2): 1765-1772.

[26] Papakostasa, K.; T. Mavromatisb, N. Kyriakis (2010). Impact of the ambient temperature rise on the energy consumption for heating and cooling in residential buildings of Greece, Renewable Energy, 2010; 35: 1376-1379.

[27] Kavgic M.; A. Mavrogianni, D. Mumovic, A. Summerfield, Z. Stevanovic, M. Djurovic-Petrovic (2010). A review of bottom-up building stock models for energy consumption in the residential sector, Building and Environment, 2010; 45: 1683-1697.

[28] Lukas G. Swan, V. Ismet Ugursal (2009). Modeling of end-use energy consumption in the residential sector: A review of modeling techniques, Renewable and Sustainable Energy Reviews, 2009; 13: 1819-1835.

[29] Nelson Fumo, A review on the basics of building energy estimation, Renewable and Sustainable Energy Reviews, 2014; 31: 53-60.

[30] Hai-xiang Zhao, Frédéric Magoulès (2012). A review on the prediction of building energy consumption, Renewable and Sustainable Energy Reviews, 2012; 16: 3586-3592.

[31] Rébha Ghedamsia, Noureddine Settoua, Abderrahmane Gouarehb, Adem Khamoulic, Nadia Saifia, Bakhta Reciouib, Boubekker Dokkar (2016). Modeling and forecasting energy consumption for residential buildings in Algeria using bottom-up approach, Energy and Buildings, 2016; 121: 309-317.

[32] Rory V. Jones, Alba Fuertes, Kevin J.Lomas (2015). The socio-economic, dwelling and appliance related factors affecting electricity consumption in domestic buildings, Renewable and Sustainable Energy Reviews, 2015; 43: $901-917$.

[33] Najmi, Ali; Hamed Shakouri G. and Abbas Keramati (2016). Energy consumption in the residential sector: a study on critical factors, International Journal of Sustainable Energy, 2016; 35 (7): 645-663.

[34] Diaoa, Longquan; Yongjun Sunb, Zejun Chenc, and Jiayu Chen, Modeling energy consumption in residential buildings: A bottom-up analysis based on occupant behavior pattern clustering and stochastic simulation, Energy and Buildings, 2017; 147: 47-66.

[35] Stamper, Eugene and Richard L. Koral (1979). Handbook of Air Conditioning, Heating, and Ventilating, Industrial Press Corp. New York, 1979. 
[36]Lienhard IV, J. H. and J. H. Lienhard V (2001). A Heat Transfer Textbook (Third Edition), Cambridge: Massatuset, USA, 2001.

[37] ASHRAE Fundamentals Handbook, Chapter 16: Ventilation and Infiltration, pp.16.21.

[38]Eurostat. https://ec.europa.eu/eurostat

[39] World Energy Council. https://www.worldenergy.org/

[40] Tokyo Electric Power Company Holdings. http://www.tepco.co.jp/en/challenge/csr/initiatives/CO2/index-e.html

[41] Energy Information Administration. http://www.eia.gov

[42] European Environment Agency (2010) report ENER 038, Overview of the electricity production and use in Europe, Published 19 March 2013 (Last modified 23 Feb 2018). Available at: https://www.eea.europa.eu/data-andmaps/indicators/overview-of-the-electricity-production/assessment

[43] OECD iLibrary. http://www.oecd-ilibrary.org

[44]Duffie, J.A. and W.A. Beckman (1993), Solar Engineering of Thermal Processes, Wiley, New York, as summarized in Maidment, Handbook of Hydrology, 1993.

[45] G. H. Hargreaves and Z.A. Samani (1982). Estimating Potential Evapotranspiration, Journal of the Irrigation and Drainage Division, 1982; 108 (3): 225-230.

[46] Shahidian, Shakib; Ricardo P. Serralheiro, João Serrano and Jose Teixeira (2013). Parametric calibration of the Hargreaves-Samani equation for use at new locations, Hydrological Processes, 2013; 27 (4): 605-616.

[47] Almorox, Javier and Jürgen Grieser (2016). Calibration of the Hargreaves-Samani method for the calculation of reference evapotranspiration in different Köppen climate classes, Hydrology Research, 2016; 47 (2): 521-531.

[48] Bindi, M. and F. Miglietta (1991). Estimating daily global radiation from air temperature and rainfall measurements, Climate Research, 1991; 1: 117-124.

[49]HOMER ENERGY (www.homerenergy.com/support/docs/3.11/published_solar_data.html). Data were taken from Duffie JA and W.A. Beckman (1991). Solar Engineering of Thermal Processes (2nd edition), Wiley, New York, NY, 1991.

[50] Sabzipour, Ali A. (2008). A simple formula for estimating global solar radiation in central arid desert of Iran, Renewable Energy, 2008; 33: 1002 - 1010. DOI:10.1016/j.renene.2007.06.015

[51] Amit Kumar Yadav and S.S. Chandel (2014). Solar radiation prediction using Artificial Neural Network techniques: A review, Renewable and Sustainable Energy Reviews, 2014; 33: 772-781. 
[52] Shakouri G., Hamed and A. Kazemi (2016). Selection of the best ARMAX model for forecasting energy demand: case study of the residential and commercial sectors in Iran, Energy Efficiency, 2016; 9 (2): 339-352.

[53] Shakouri G., Hamed and R. Nadimi (2009). A Novel Fuzzy Linear Regression Model Based on a Non-Equality Possibility Index and Optimum Uncertainty, Applied Soft Computing, 2009; 9 (2): 590-98.

[54] Almorox, Javier (2011). Estimating global solar radiation from common meteorological data in Aranjuez, Spain, Turk J. Physics, 2011; 35: 53 - 64. DOI:10.3906/fiz-0912-20.

[55] Thornton, Peter E. and Steven W. Running (1999). An improved algorithm for estimating incident daily solar radiation from measurements of temperature, humidity, and precipitation, Agricultural and Forest Meteorology, 1999; 93: 211-228.

[56] Li, Huashan; Fei Cao, Xianbiao Bu and Liang Zhaod (2015). Models for Calculating Daily Global Solar Radiation from Air Temperature in Humid Regions_A case study, Environmental Progress \& Sustainable Energy, 2015; 34 (2): 595-599. DOI 10.1002/ep.12018.

[57] DizEE Degree Days, Weather Data for Energy Professionals. www.degreedays.net [accessed April 2019].

[58] Various web sites: House size comparisons (www.greenlivingpedia.org/House_size_comparisons), International House Sizes (demographia.com/db-intlhouse.htm), Apartment Therapy (www.apartmenttherapy.com), How much space is enough? Average residential floor space per capita in $\mathrm{m}^{2}$ (shrinkthatfootprint.com/wpcontent/uploads/2013/04/Percapita.gif). [accessed April 2019].

[59] Jakubcionis, M. and J. Carlsson (2017). Estimation of European Union residential sector space cooling potential, Energy Policy, 2017; 101: 225-235.

[60] Papakostas, K. and N. Kyriakis (2005). Heating and cooling degree-hours for Athens and Thessaloniki, Greece, Renewable Energy, 2005; 30: 1873-1880

[61] Satman, A. and N. Yalcinkaya (1999). Heating and cooling degree-hours for Turkey, Energy, 1999; 24: 833-840.

[62] The World Bank (Data). http://data.worldbank.org/indicator/ (Labor Force and Unemployment, Electricity Generation and Loss, and Carbon Emission data) [accessed April 2019].

[63] UN-HABITAT For a better urban future. http://unhabitat.org [accessed April 2019].

[64] Youth Xchange, Towards Sustainable Lifestyles. http://www.youthxchange.net [accessed April 2019].

[65] Key World Energy Statistics 2014, IEA. Available online: www.iea.org [accessed April 2019].

[66] Households Income and Expenditure Statistics (2010). Statistical Center of Iran, www.amar.org.ir ; 2010_[accessed April 2019]. 
[67] Randall, D.A.; R.A. Wood, S. Bony, R. Colman, T. Fichefet, J. Fyfe, et.al. (2007). Climate models and their evaluation. In Climate Change, 2007: The physical science basis. Contrib. of Working Group I to the Fourth Assess. Report of the Intergov. Panel on Climate Change [Solomon, S., et.al. (eds.)]. Cambridge: Cambridge Univ. Press; 2007, p. 589-662.

[68] Meehl, G.A.; T.F. Stocker, W.D. Collins, P. Friedlingstein, A.T. Gaye, J.M. Gregory, et.al., 2007: Global Climate Projections. In: Climate Change 2007: The Physical Science Basis. Contrib. of Working Group I to the Fourth Assess. Report of the Intergov. Panel on Climate Change [Solomon, S., et.al. (eds.)]. Cambridge: Cambridge Univ. Press; 2007, pp 749-854.

[69] Scheffer, M., Brovkin, V., \& Cox, P. (2006). Positive feedback between global warming and atmospheric CO2 concentration inferred from past climate change. Geophysical Research Letters, Vol 33, Issue 10 , May 2006. doi.org/10.1029/2005GL025044.

[70] Matthews, H.D.; N.P. Gillett, P.A. Stott and K. Zickfeld (2009). The proportionality of global warming to cumulative carbon emissions, Nature, 2009; 459: 829-832.

[71]Zickfeld, K.; A.H. MacDougall and H. Damon Matthews (2016). On the proportionality between global temperature change and cumulative $\mathrm{CO} 2$ emissions during periods of net negative $\mathrm{CO} 2$ emissions, Environmental Research Letters, 2016; 11: 055006.

[72] Global Time Series, Climate at a Glance, Climate Monitoring, National Oceanic and Atmospheric Administration: http://www.ncdc.noaa.gov/cag/time-series/global. [accessed April 2019]

[73] Shakouri G., Hamed and M.B. Menhaj (2008). A single fuzzy rule to smooth the sharpness of mixed data: Time and frequency domains analysis, Fuzzy Sets and Systems, 2008; 159: 2446 - 2465.

[74] Michel De Rougemont (2015). Temperature Anomalies and Carbon Dioxide, a Correlation Attempt, HAL Archives-ouvertes, Jul. 2015. http://hal.archives-ouvertes.fr/hal-01146608v3. [accessed April 2019]

[75] Le Quéré et al. (2017). Global Cabon Project, Global Cabon Budget 2017. doi.org/10.18160/GCP-2017. http://www.globalcarbonproject.org/carbonbudget. [accessed April 2019]

[76] Dlugokencky, Edward and Pieter Tans (2016), NOAA/ESRL. Trends in Atmospheric Carbon Dioxide. Global Monitoring Division, Earth System Research Laboratory. National Oceanic and Atmospheric Administration. https://www.esrl.noaa.gov/gmd/ccgg/trends/gl_data.html. [accessed April 2019] 
[77] Shakouri G., Hamed and M.B. Menhaj (2008). A Systematic Fuzzy Decision-Making Process to Choose the Best Model Among a Set of Competing Models, IEEE Syst. Man Cyber., 2008; 38 (5): 1118 - 1128.

[78] Rogelj, Joeri; Malte Meinshausen and Reto Knutti, (2012). Global warming under old and new scenarios using IPCC climate sensitivity range estimates, Nature Climate Change, 2012; 2: 248 - 253.

[79] Peters, G.P.; Robbie M. Andrew, Tom Boden, Josep G. Canadell, Philippe Ciais, Corinne Le Quéré et.al. (2013). The challenge to keep global warming below $2{ }^{\circ} \mathrm{C}$, Nature Climate Change, 2013; 3: 4 - 6 .

[80] Boer, G.J.; R.J. Stouffer, M. Dix, A. Noda, C.A. Senior, S. Raper and K.S. Yap (2002). Projections of Future Climate Change. In: Climate Change 2001: The Scientific Basis. IPCC. Cambridge: Cambridge University Press; 2002, p. 527-578.

[81]EnerData, Global Energy Statistical Yearbook 2018, https://yearbook.enerdata.net. [accessed April 2019]

\section{Appendix: ARMAX models.}

System Identification is a math field for exploring relationships between measured variables in a system, where statistical methods are applied for modeling dynamic systems. One common approach is modeling systems regardless of any internal complicated interactions (like what is seen in Figure 1) as black-boxes. It means that no information from inside the system is needed/available. Among from various structures used for black-box system identification, the Autoregressive Moving Average (ARMA) model provides a parsimonious description of a (weakly) stationary stochastic process. The model can be described by two lag polynomials, one for the autoregression (AR) and the second for the moving average (MA). The latter usually involves modeling the error term; however, including eXtra independent input signal(s) an ARMAX structure is formed as follows:

$$
y(t)=c+\sum_{i=1}^{n_{\alpha}} \alpha_{i} y(t-i)+\sum_{i=0}^{n_{\beta}} \beta_{i} u(t-i)+\sum_{i=0}^{n_{Y}} \gamma_{i} e(t-i)
$$

where $y(t)$ is the black-box's output variable, $u(t)$ denotes its input, and $e(t)$ is an independent identically distributed random variable (i.i.d.), sampled from a normal distribution with zero mean, so called white noise. The model structure can be represented by a thriple $\left(n_{\alpha}, n_{\beta}, n_{\gamma}\right)$, where the three parameters define system lags fir the output, the input, and the error term, tespectively.

ARMAX models are applied in this research for the development of experimental relationships between variables, where the parameters are estimated based on historical measurements. Although static linear curve fitting might be sufficient for extracting the required coefficients, ARMAX model is preferred to capture effects of the past values of both dependent and explanatory variables, as well as the dynamics in error terms.

See L. Ljung, System Identification: Theory for the user, 1998, Prentice Hall. 